University of Louisville

ThinkIR: The University of Louisville's Institutional Repository

$12-2010$

\title{
More real than real : an anthropological and phenomenological exploration of imagistic sacred space in the contemporary elegy and fine art photograph.
}

Amy Liann Tudor 1968-

University of Louisville

Follow this and additional works at: https://ir.library.louisville.edu/etd

\section{Recommended Citation}

Tudor, Amy Liann 1968-, "More real than real : an anthropological and phenomenological exploration of imagistic sacred space in the contemporary elegy and fine art photograph." (2010). Electronic Theses and Dissertations. Paper 1467.

https://doi.org/10.18297/etd/1467

This Doctoral Dissertation is brought to you for free and open access by ThinkIR: The University of Louisville's Institutional Repository. It has been accepted for inclusion in Electronic Theses and Dissertations by an authorized administrator of ThinkIR: The University of Louisville's Institutional Repository. This title appears here courtesy of the author, who has retained all other copyrights. For more information, please contact thinkir@louisville.edu. 
MORE REAL THAN REAL: AN ANTHROPOLOGICAL AND PHENOMENOLOGICAL EXPLORATION OF IMAGISTIC SACRED SPACE IN THE CONTEMPORARY ELEGY AND FINE ART PHOTOGRAPH

By

Amy Liann Tudor

B.S., Towson State University, 1990

M.F.A., Virginia Commonwealth University, 1993

\author{
A Dissertation \\ Submitted to the Faculty of the \\ College of Arts and Sciences of the University of Louisville \\ in Partial Fulfillment of the Requirements \\ For the Degree of
}

Doctor of Philosophy

Department of Humanities

University of Louisville

Louisville, Kentucky

December 2010 
Copyright 2010 by Amy Liann Tudor

All rights reserved 


\section{.}

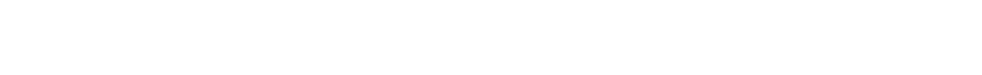

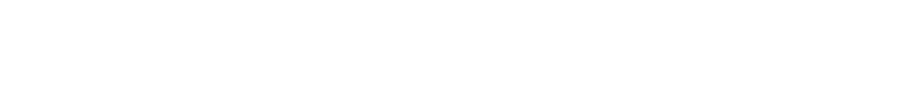

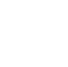

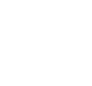

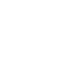

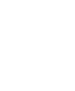

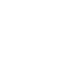

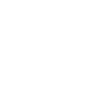

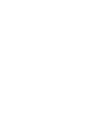

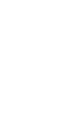

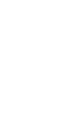

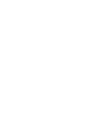


MORE REAL THAN REAL: AN ANTHROPOLOGICAL AND

PHENOMENOLOGICAL EXPLORATION OF IMAGISTIC SACRED SPACE IN THE CONTEMPORARY ELEGY AND FINE ART PHOTOGRAPH

\title{
By
}

\author{
Amy Liann Tudor \\ B.S., Towson State University, 1990 \\ M.F.A., Virginia Commonwealth University, 1993
}

A Dissertation Approved on

November 4, 2010

by the following Dissertation Committee:

Dissertation Director 


\section{ACKNOWLEDGMENTS}

I would like to thank Dr. Anna Secor, Dr. Denise Fulbrook, and Dr. Monica Udvardy at the University of Kentucky for the foundational theory courses that became the "bones" of this work. Professor Kim Edwards and Professor Nikky Finney also provided invaluable assistance on my creative work, for which I am very grateful. From the University of Louisville, I would like to thank Dr. Osborne Wiggins, Dr. Sena Jeter Naslund, and Professor Mary Carothers for graciously agreeing to serve on my dissertation committee and for unfailingly supporting my research.

I am also indebted to the friendship and guidance of Sara Northerner, Paul Taylor, Julie Marie Wade, Carol Stewart, Angie Griffin, Steve Watkins, Anne Zell, Shari Long, Amanda Collier, Monica Krupinski, James Leary, Jessica Maupin Leary, Michelle Del Toro, and Lori Hamilton. I could not have completed this work-or enjoyed its process nearly as much-without them.

I am especially grateful to Dr. Annette Allen, the director of this dissertation committee and my advisor and mentor throughout my work toward this degree. Her careful guidance, intelligence, humor, and friendship have made this work possible.

And of course, love and thanks to Revely Culver for her patience and constant support throughout the completion of this work. 


\section{ABSTRACT \\ MORE REAL THAN REAL: AN ANTHROPOLOGICAL AND \\ PHENOMENOLOGICAL EXPLORATION OF IMAGISTIC SACRED SPACE IN THE CONTEMPORARY ELEGYAND FINE ART PHOTOGRAPH}

Amy Liann Tudor

November 4,2010

The creation of liminal spaces has been used for centuries cross-culturally to create sacred or taboo meanings in rituals, people, places, or objects. Liminality is constructed by the overlapping of cultural categories and "ruptures" an object or event's connotations, imbuing it with new and often transcendent or spiritually charged meaning. The photograph is an example of liminal space, since it freezes even the living in a state of corpse-like stasis. With the invention of this new medium, as well as its application to memorializing the dead, previous forms of commemorating death such as the eulogy and the poetic elegy were supplanted.

Though the poetic elegy form has continued, it has done so with significant departures from its traditional tropes. Combined with a cultural loss of connection with the pastoral, an alteration of the cultural conceptions of "the Good Death," and a progressive, phenomenological extension of the horizon of meaning of death, the elegy form has undergone a transformation. Instead of relying on traditional, narrative poetic forms, the contemporary attempts to replicate the photographic images' liminal, sacred 
space in literary form. Through this shift to an attempted replication of the visual form, elegiac poetry has incorporated elements of surrealism, magical realism, and other "transgressive" literary forms. This allows the poems to capture a more authentic and contemporary experience of modern and postmodern cultural understandings of death, grief, and the corpse.

In the first section, this work traces this movement by looking at the development of theories of liminality in the field of anthropology, and then follows the genesis of this "state between states" in six other disciplines: corpse theory (which is, in itself, an interdisciplinary field), phenomenology, history, painting, photography, and finally poetry itself. This dissertation also explores the shift in cultural interpretations and meanings of death and the marked changes in understandings and experiences of the Sacred in relation to death, the corpse, and the practice of mourning. The second section of the dissertation contains an application of this approach to liminality in the elegy in individual poetic works from Loose Horses, a collection of poetry in progress. 


\section{TABLE OF CONTENTS}

\section{PAGE}

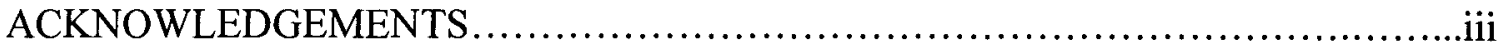

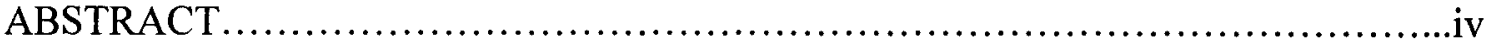

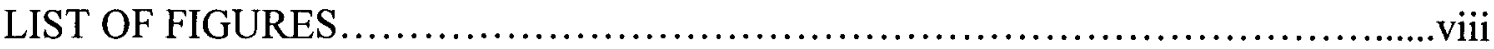

SECTION I: Issues of the Sacred in the Corpse, the Elegy, and the Photograph...........1

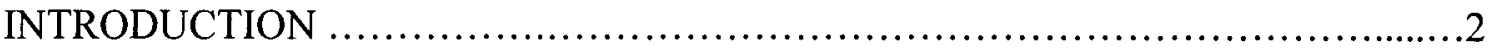

Chapter I: Symbolic Systems and the Creation of the Sacred and Taboo................8

Chapter II: The Corpse as Liminal Space......................................... 14

Chapter III: The Traditional Elegy........................................... 19

Chapter IV: "The Good Death" and the Roots of the Modern Desacralization..............26

Chapter V: War in the $20^{\text {th }}$ Century and the Death of Dulce et Decorum Est............29

Chapter VI: The Frozen Frame..............................................39

Chapter VII: The Decline of the Corpse's Sacred Cultural Space......................48

Chapter VIII: A Bridge Too Far: Joel-Peter Witkin and Gods of Earth \& Heaven//.....54

Chapter IX: Photography's Turn: Sally Mann and What Remains ......................61

Chapter X: The Elegy's Turn: Seamus Heaney and the End of the "Saccharined Death".

Chapter XI: Phenomenology and Poetry: A Method of Expectation......................79

Chapter XII: The Architect's Brother: Robert ParkeHarrison and the Photo's Abandonment of Narrative .............................................93 
Chapter XIII: The Clock Face: A Place in the Canon...................................97

SECTION II: Excerpts from Loose Horses ..................................................110

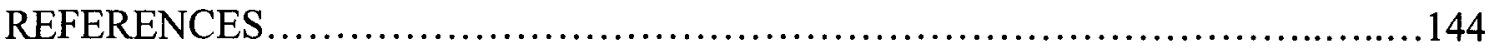

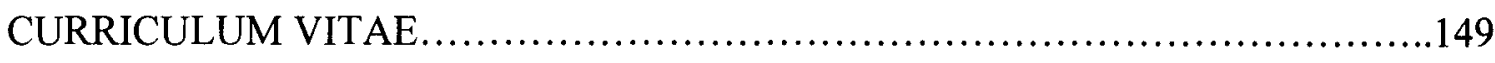




\section{LIST OF FIGURES}

\section{FIGURE}

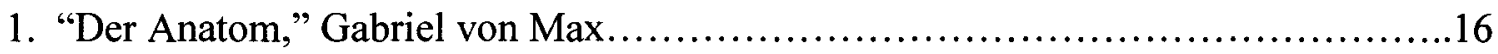

2. The Corpse as a Liminal Object in Symbolic Systems...............................17

3. "Victorian Post Mortem Photograph," Anonymous..................................40

4. "Dead Confederate Soldier, Petersburg, 1865," Mathew B. Brady....................41

5. "Confederate Dead, Spotsylvania County Courthouse, 1865," Mathew B. Brady.....42

6. "The Anatomy Lesson of Dr. Nicholaes Tulp," Rembrandt von Rijn.................49

7. "Death of a Loyalist Militiaman," Robert Capa..................................51

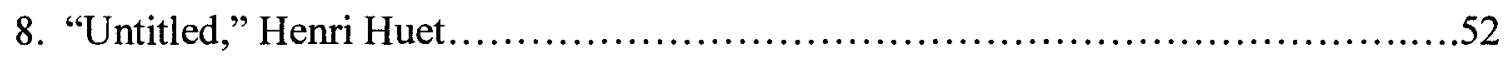

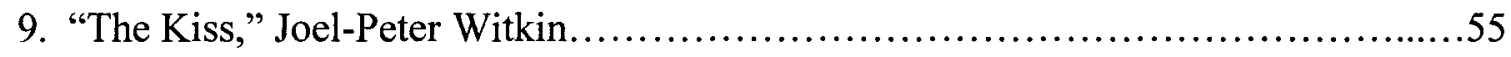

10. "Counting Lessons in Purgatory," Joel-Peter Witkin............................56

11. "Untitled," Sally Mann...................................................63

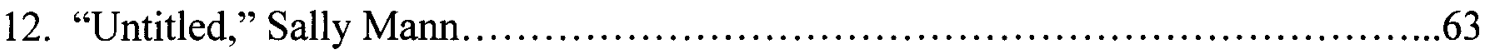

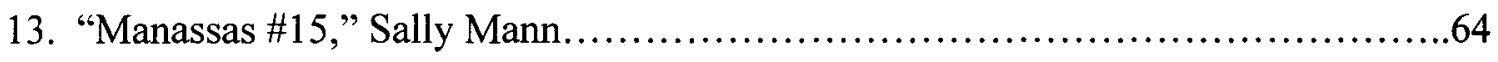

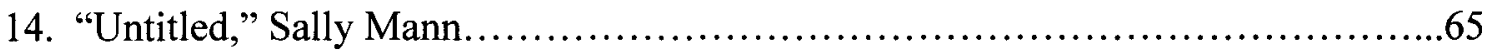

15. "Earth Elegies," Robert ParkeHarrison.........................................94

16. "Garden of Selves," Robert ParkeHarrison...................................... 
SECTION I: ISSUES OF THE SACRED IN THE CORPSE,

THE ELEGY, AND THE PHOTOGRAPH 


\section{INTRODUCTION}

We begin with the scene of a crime. An intruder has entered a home and discovered the objects of value he seeks: a television, a personal computer, jewelry and money, all left in their casual resting places within the home's private walls. Before he leaves, however, the intruder goes through the refrigerator, and, on finding something to drink, sits in the family's living room to search through another prize the family photo albums he discovered sitting out on a shelf. Hidden inside the quiet house, he flips through each page of the albums, taking the occasional photo ostensibly (he will tell authorities later, should he be caught) to mark his memory of this intimate space.

This scenario may sound far-fetched in our crime-drama world where the intruder is always a brilliant mind too fixated on objects of material wealth to bother with something as trifling as a photograph. The scenario also pales in comparison to such scenes where the inhabitants are murdered, and instead of an open photo album that is missing pictures (like a ruined mouth missing teeth), we find bodies strewn around the scene of the crime. However, this intruder in the living room and the open, defaced albums are quite real and his crime more common than many would believe. In his excellent book Last Flesh: Life in the Transhuman Era, Christopher Dewdney cites a 1998 study that found that in 40 percent of all break-ins in the United States, the crime scene showed evidence that photos and photo albums had been handled or taken by 
intruders (54). Though Dewdney characterized these voyeurs as "bankrupt shoppers acquiring the lifestyles they can't afford," this seems an oversimplification, especially since the study went on to show that the victims of these crimes found the photos' viewing and theft (and not the loss of valuable property) the most distressing feature of the robberies, a violation of their private space.

There is something sacred about a lived-in space. Family homes, passed down from generation to generation, are a mainstay of the mythos of American culture, and the intruder who comes into this place is an equally present mainstay of contemporary entertainment, the stranger's entrance into the quiet home somehow tantamount to sacrilege. Those who have had their houses broken into cannot help but feel an end to the sense of safety they once had in their homes, and it is not uncommon to find homes that have been violated becoming fortified with extra locks, security systems, and closed blinds and drapes.

There is also something sacred about the private moments a photograph freezes within its frame, primarily because they are frozen, the photo becoming a place where an instant of time passes before the lens (and thus toward the viewer) and stands still. As Roland Barthes explores in Camera Lucida, in the small, fragile space of the photograph, something that was alive in its present becomes -- in its stillness, its lack of existence in the present of the viewer -- a representation of death. One need only recall a photo of a loved one who has since died to understand how the photograph stops the living moment, the face of someone who no longer exists gazing back, phantom-like, from behind the frame. 
While it is true that there are no bodies at the scene of the intruder in the sacred space of the living room, the family album in his hands, the stranger who looks at the album or carries photos away has, in fact, committed two attacks. First, he has imprinted a profane intrusion onto the house. Second, he has disturbed photos that hold personal history, personal "deaths." The victim's distress at the dual intrusion is understandable in this context, since there has thus been both a "murder" of a private sense of safety and a violation of "the dead."

Still, both the thief and the victim's responses in this scenario are curious. The fierce attachment to the house and its valuable contents is obvious, but why such attention to the photographs? What is it about their small space that seems to hold so much meaning for those who take them, collect them, and put them on display? Their content is obviously representative of important things, but the photos themselves clearly represent something larger in the way they freeze experience, holding it between the present and the "lived," and history and memory, a physical representation of the liminal space - the threshold or passage - between these states.

If one returns to the intruder, to the sacred nature of the house and its violation, one notices the same presence of liminality. The house is no longer safe, the albums no longer private, even though they of course go on existing behind their doors and their covers, tucked away once again when the room is reassembled and the police and the onlookers have all gone away. Like the photographs hold that moment between present and past, the house now sits suspended in this liminal space between clear categories, private but once public, safe but now, simultaneously tinged with the unsafe. The liminality of 
the photograph is what makes its viewing a violation of something sacred, while the intruder's entrance to the house now makes the house's sacred space profane.

Extend the scenario now. Imagine a body left behind, an inhabitant of the house killed as he entered the room where the thief sat, viewing the photographs. The remaining members of the family view the body of their loved one, the corpse no longer the person he was to them, and yet also not yet memory, a body caught - as he is in the photograph of the album open on the floor beside him - between life and death. Like the photo, like the house, the corpse is now caught in its own liminal state, one that many still living find unending in its association with the corpse's resting place. The family abandons the house, the space "tainted" by the death.

Culture shows us this phenomena everywhere; it is one of the most enduring elements of many American myths: the house in Norfolk, Virginia deemed "unmarketable" after a psychiatrist, still practicing in a posh office a few miles away, buries his wife in the dirt basement; the roadside markers lining the highways to mark not graves but sites of discorporation in vehicular deaths; the Civil War battlefields lined with split-rail fences and somber markers across the eastern coast of the United States.

This liminal quality, the state of being "in between," is the common element in the corpse, the photograph, and the physical space, and where the liminality doubles and redoubles - as in the violation of the photographs coupled with that of the space, or the introduction of a single death (or thousands) into a physical place - so do the connotations of reverence and separateness (the sacred) or repulsion (the profane). The photograph of the corpse is thus the most potent example of liminality and its ability to "imprint" these connotations, all three undefined states frozen in the camera's (and its 
Operator's) gaze. This particular genre is, in fact, less centered on its subject of corpses and death than it is on capturing this liminal state, its "take" of the rupture of past and present, life and death, individual and his or her physical space. Photography is so adept at this capturing of "threshold" that it can, on its own, imprint for its spectator death on a physical space.

Now, push the photograph's meaning further. Perhaps at its core, the photograph is about commemoration - of a moment, an event, a person. So it is in literature with the elegy form which, like the photograph of the dead, memorializes, captures, and depicts. In these poetic lines, a person is remembered for who he was to the writer with very specific and personal detail. In the past, the elegy used very specific "rituals" in its writing in an effort to go through a "work" of mourning and proper commemoration, including the use of refrains, references to Classical (and thus timeless) works of literature, and transformations of the dead into eternal, vegetative gods or goddesses living on the perpetually renewing landscape. In this way, these tropes helped to place a hand up to death itself, the dead living once again in the perpetuity made possible by metaphor and verse.

But with the dawning of modernity, the elegy's form - unchanged for centuries began to change, just as-as we shall see-the depiction of death in the photograph would began to change. In the elegy, writers abandoned the traditional forms, in some cases rebuking the reader and the poet herself for their use. There was no unchanging landscape on which to rely, the pastoral replaced with the blasted fields of Flanders, the blighted landscapes of industrial England, the now-frightening woods of Poland and Germany filled with vicious dogs and even more vicious men. In the photograph, the 
medium moves beyond commemorating the death to capturing death itself, its moment on the battlefield. It moves from capturing the individual for the sake of remembrance to something else, something that verges - by the late- $20^{\text {th }}$ century —on fetishism in the works of photographers like Wee Gee and Joel-Peter Witkin.

But why is this the case? Death is death, and it has always been the same. Or has it? What is it about the so-called "Modern Age" that altered this poetic form? Answering this question is the subject of this work, and in what follows, we will see that the answer to it lies in the particular characteristics of modernity itself, in its ambivalence about what I shall call belief, in its rapid technological advancement, and its growing movement toward-and fight against-the loss of the individual, in both life and death. This is the movement that has given us both the contemporary elegy form and the work of many fine art photographers who deal with death and the dead.

It is also what has given us the thief who enters the house, finds the photo album, and sits and looks and looks. He looks at his victims, yes, but he also looks for himself, and sometimes finds it, finds something worth having in those permanent images-and only in the image - that he tucks in a pocket and takes away. 


\section{CHAPTER I}

\section{SYMBOLIC SYSTEMS AND THE CREATION OF THE SACRED AND TABOO}

To begin this exploration, it is necessary to have an understanding of the primary theoretical underpinning of this work, which is the anthropological theory of liminality and how this state aids in the creation of transcendent or sacred meanings in a given culture and its artifacts. The concept of liminality as the key to the creation of the sacred, or taboo, is explored in the work of two noted anthropologists, Mary Douglas and Edmund Leach, both of whom did their work in this area in the mid-1960s. Both follow the creation of symbolic systems in various cultures, systems that carve out experience into distinct symbolic and cognitive categories. Objects and experiences are placed into these categories as a result of their use in the society and become signifiers for aspects of the culture's sociological structure. These connotations guide both behavior and belief and organize the world into logical categories, allowing people to avoid feelings of chaos, which humans abhor.

Douglas, who did much of her work with African tribes and religions, defined the word taboo as "a spontaneous device for protecting the distinctive categories of the universe" (Douglas xi). Taboo, she stated in her book Purity and Danger, "protects the local consensus on how the world is organised. It shores up wavering certainty. It reduces the social and intellectual disorder" (xi). Primarily interested in the concept of pollution (what she calls "dirt" throughout the book), Douglas found that taboo occurred 
when something was taken out of its prescribed cognitive category and became ambiguous, a state which caused "cognitive discomfort" (xi). "Taboo confronts the ambiguous and shunts into the category of the sacred" (xi). In fact, Douglas uses the words "sacred" and "taboo" interchangeably to imply something that takes on elevated, symbolic value beyond its literal meaning that begins to dictate its cultural use.

A small example common to most readers illustrates Douglas' conclusions about taboo and its relation to "dirt," a concept that she summarizes later in the book as "matter out of place" (44). If, as stated above, the universe is separated into cognitive categories, human hair would fit into a specific category. In U.S. culture, a person's hair is associated with grooming, often connoted with beauty and cleanliness. Within its own cognitive category, hair is prized and cared for. People run their fingers through their lover's hair and compliment one another on its appearance. Parents style and wash their children's hair, and people are lauded for their skill in cutting and innovating the way it looks. In another category, this one is an elevated category for "food," there is the experience of eating a meal at a restaurant. Unlike the food prepared and eaten at home, there are immense expectations for food prepared and served at a restaurant: it should be cooked well, its taste should be pleasing, and its presentation should be even more impressive than food served at home, particularly since it is purchased and should therefore reflect a "worth" equal to its higher cost.

Within their separate categories, these two objects have positive value. However, a common taboo in U.S. culture occurs when these two categories overlap. If a person pays for a meal at a restaurant and it arrives with a hair in it, he or she will likely send the food back, repulsed at the idea of a human hair in a plate of expensive food. The hair 
falls from its category of "grooming" and overlaps with that of "food," thus becomes ambiguous in its meaning. The hair is particularly offensive because it belongs to a stranger, and all bodily items (hair, spit, fingernail clippings) carry a liminal connotation in their own right: they are both part of the person who has discarded them and not, a state which makes them harder to categorize and thus the prime objects of taboo.

Edmund Leach developed a similar theory about the concept of taboo, though Leach, a linguist, was focused on linguistic overlaps. In "Animal Categories and Verbal Abuse," Leach traces the development of the distinct cognitive categories humans hold as adults, saying that childhood is actually marked by an absence of these. Rather, children exist in an unbroken continuum that does not contain distinctive objects or things. As they grow older, children are taught the specific pattern that their culture uses to separate things into categories, with each delineated by a name. These basic discriminations "should be clear-cut and unambiguous," Leach states, "[and] there must be absolutely no doubt about the difference between $m e$ and $i t$, or between we and they" (35). "Language gives us the names to distinguish the things; taboo [allows] the recognition of those parts of the continuum which separate the things" (35).

Along with Douglas, Leach concludes that it is these liminal things - those that exist between the categories - that become sacred or taboo. The example of child pornography illustrates its connotation as taboo in contemporary U.S. culture. In one category, the culture places "child," with all its attendant meanings of innocence and inexperience. In the other category is sexual behavior, with its associations with adult experience and, typically, procreative ability. These two categories have opposing meanings, and thus their overlap in sexually explicit material that depicts children results 
in the cultural taboo, in this case, the violation of the sacred (elevated) quality and a descent into the perverse or profane.

Both Douglas and Leach use this theory of the overlapping of symbolic system to explain how objects "lift away" from their prescribed categories of ordinary use and take on qualities of the sacred, imbued with symbolic (though not necessarily "religious") value dictating its common use. In some cases, as with the hair and the pornographic materials, this sacred nature is in the form of revulsion and marginalization. Other liminal areas elevate objects or experiences to the point of reverence as they take on layers of metaphor and meaning like skin.

For the purposes of this discussion, it is important to draw a distinction between the sacred in its anthropological context and the concept of religion. Religious traditions are actually outcroppings of a society's anthropological constructions of cultural meaning. Thus, a culture first experiences objects or ideas and attempts to categorize them. Those that fit neatly into categories fall into the realm of mundane objects of common use and connotation. Those that do not - those that are liminal - cause cognitive discomfort for members of that society, and they are shunted into the realm of the sacred or profane, dependent on their cultural interpretation. Thus, sacred connotations precede religious connotations, and religious connotations are developed to explain the idea or objects' liminality and sacred nature.

Two examples may help to clarify this concept. The first comes from sociologist and social theorist David Emile Durkheim. Durkheim theorized that the sacred is always separated in some way from the mundane; in fact, he believed that "...rules of separation are the distinguishing marks of the sacred..." (Douglas 26). This distinguishing "mark" 
helps to explain the "fictive, abstract nature of religious entities" seen across cultures. These entities are, Durkheim stated, "merely ideas awakened by the experience of society, collective ideas projected outwards, mere expressions of morality" (26). Since this is the common anthropological experience across cultures, deities "have no fixed material point of reference," and are "rootless, fluid, liable to become unfocused [or to] flow into other experiences" (26). This illuminates the order of construction of the sacred: the culture experiences reality, agrees on proper modes of behavior and social conscience through these experiences, projects them outward away from the individual in an effort to elevate them above mere individual concern, and creates this sacred, formless deity that holds these projections. Thus, from anthropological roots, Yahweh, Buddha, Allah, Zeus....all are born.

An even clearer example of the use of anthropological concepts of liminality creating religious tradition can be seen in the Judaic tradition in the long list of "do's" and "don't's" found in the Biblical books of Deuteronomy and Leviticus. Anthropologist Mary Douglas explains the dietary prohibitions that traditional Jews still follow are organized around the animals' bridging of categories, which forces them into profane liminal space. Particularly, Douglas says, the categories were defined by how closely the animal adhered to the divisions of earth, waters, and sky. Fish with fins and scales are considered "clean" because they are made solely for existing in the water by their design and their means of propulsion. But smooth fish such as eel are not clean. Eel have no scales and do not use fins for propulsion, making them improper members of the "fish" category. Thus, they are considered "unclean." Likewise, four-footed animals that fly are unclean (an overlap of earth and sky), as are any animals that have "hands" for front 
feet (such as lizards or crocodiles) yet insist on going on all fours anyway (an improper use of hands). Reptiles go on dry land, but not as quadrupeds. Some insects fly, but not as birds, and along with the others, their inability to fit into the proper environmental category sends them off into the realm of "unclean" (Douglas 68-71). Thus, from anthropologically driven cognitive discomfort, religious tradition is defined and practiced, even to the present day ${ }^{1}$.

Like these "unclean" creatures, the dead body or corpse is also an ambiguous object, existing as both a living person, still recognizable as the living individual, and as the dead body that is beginning its inevitable process of decomposition from the moment of death. In the next chapter, we will discuss this concept, including the ways the living are aware of this liminal state of the corpse, as evidenced by a nearly universal preoccupation with proper burial practices and places of discorporation such as battlefields. These are the places where the unknown of death punches a hole in the certainty of the land of the living, allowing the corpse to "live," if even for a moment, in this sacred and taboo liminal space.

\footnotetext{
${ }^{1}$ Levitican laws forbidding homosexuality and bestiality are likewise driven by liminal space, for two reasons. First, they were the practice of foreign nations, and incorporating the practices of neighboring nations or conquered peoples "muddied the waters" of the culture's singular identity. Second, sexual intercourse was intended only for procreation, and sex for any other purpose took this activity out of its own culturally prescribed category, as well.
} 


\section{CHAPTER II}

\section{THE CORPSE AS LIMINAL SPACE}

The bodies lay only a few yards apart, so just by pacing back and forth through the weeds I could see that each of them was at the same stage of decay. They had both been killed at about the same time - not too long ago, judging by the faintly lighter green of the grass peeking out from

underneath their bodies. If they'd been there more than a few days, the grass would have yellowed; if they'd been here longer than that, it would have died completely.

- Forensic anthropologist Emily Craig

In his delirium he spoke of his exile: 'Let us go, bring my luggage on board. They do not want us in this country. Let us go.' The ship that was to bear him away lay waiting in the harbor - it was the ship of the dead.... Let us look at this ship. Where is it waiting? Where is it going? What sort of journey does it provide? This ship is the ship of figuration. It is death itself, and while nothing could be more literal than the corpse, harbinger of nothingness, yet is the very concreteness of this finis which provides the ship with its amazing capacity for travel. - Michael Taussig

These two passages, the first from Emily Craig's popular forensic science text Teasing Secrets from the Dead, and the second from Michael Taussig's ethereal theoretical exploration The Magic of the State, illustrate a fundamental split in the discussion of the corpse, the split between positivistic and hermeneutic interpretations of its meaning. It is the age-old disjunction between empiricism and interpretation, between science and art. Regardless of how exactly science works to categorize, classify and easily reference death through its study of the corpse, it cannot shake the enormous metaphorical weight the culture lays on the dead body in an effort to come to some level of understanding of death. 
Even Craig, the forensic anthropologist who penned the first passage to show the chemical alteration the body imposes on its resting place, delves into the metaphorical and empathetic side of death later in her book when she reconstructs the skull of a murder victim. As Craig drips water down from the corners of the victim's face to assure her reconstruction's symmetry, she is so moved by the anguish and pain signified in the face of the "crying," violated victim that Craig herself, an empirically minded scientist, begins to weep (Craig 9-12). It is an unscientific response: the head she has made isn't the victim, after all, but only a metaphor for the woman, a liminal object existing in a liminal space. The victim is, in this case, both in Craig's present and yet lost in the past, just as the tears are only metaphorical for her pain.

Taussig's passage points to the liminality of the corpse most plainly, and ironically it is not the language of science that illustrates this state but the language of metaphor. The corpse is a "ship," a vehicle of figuration, laying in wait in the harbor of the crime scene, the ground, the morgue. Like a ship that has set sail from one port to a destination, the corpse is neither "here" on the shore of the living, the only shore we can know in this journey, or "there" in the afterlife we can only describe in the language of our "living" experience.

Though there is tremendous conjecture cross-culturally about what happens after death, what we know absolutely of it is contained only in the presence of decomposition and decay. The dead body, like the ship in the harbor or the ship at sea but still in sight of the shore, suspends itself in liminality, still recognizable as the living and not yet far enough from the shore to have vanished into decay. It is the corpse's stillness and stasis 
between these harbors, its unwavering "concreteness," that gives it its "capacity to travel," to hold such enormous metaphorical weight.

Literary critic Elisabeth Bronfen explores this liminality in relation not only to the stasis of the corpse but also to its beauty in relation to the ubiquitous presentations of female corpses in art. In her book Over Her Dead Body: Death, Femininity and the Aesthetic, Bronfen interprets the painting shown in Fig. 1, Gabriel von Max's Der Anatom, which was first exhibited in 1869 (3-4). Here, Bronfen says, the artist was "clearly influenced by the spiritualist practices of his time..." Bronfen states, practices that "...maintained that at the sight of figuratively deadened feminine body the immaterial realm of the beyond could become visible....and that the boundary between the here and the beyond blurred" (4). In Der Anatom, one of many paintings von Max completed depicting humans at the portal or threshold between life and death, a female corpse lies on the autopsy table, her body shrouded with a sheet but her beautiful, youthful features exposed. Beside her, a male anatomist sits, his hand drawing the sheet up to reveal her left breast, his other beneath his chin, as if to accentuate a state of deep thought.

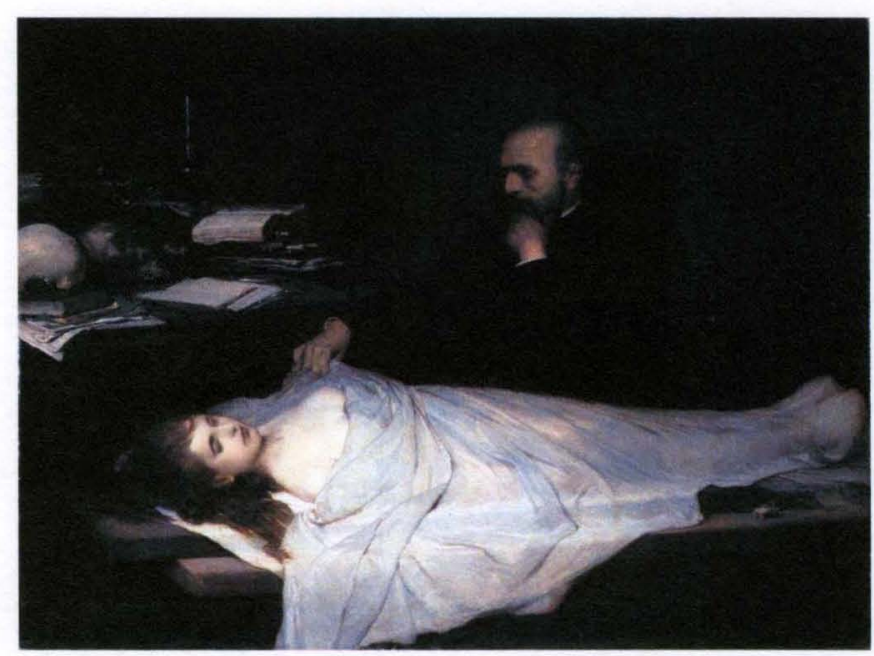

Fig. 1: Gabriel von Max, "Der Anatom," http://www.niilismo.net/forum/images/ uploads/DerAnatom.jpg 
The moment von Max has chosen to arrest in his painting is one where beauty is defined in its contrast to destruction. On the one hand, the soul has departed from the woman's body, but her beauty has not yet begun to disappear, as it will in the natural process of decay. On the other hand, the anatomist has not yet begun his dissection, in the process of which he will cut into and destroy the lines of her perfectly shaped body. The painting enacts a crucial moment of hesitation...

\section{(Bronfen 5)}

The painting becomes a metaphor for the liminality of both beauty and death in this representation, the "caught" nature of these two concepts further accentuated by the stasis of the painting itself. The painting perpetually extends this instant before the dissection, before decay, within its frame. The corpse becomes the overlapping of symbolic categories and systems - life and death, individual identity and the loss of name to the "corpse" or "body" designation, present and past. The body in von Max's painting is beautiful (revered) but also dead (repulsive). It is the point of intersection (Fig. 2).

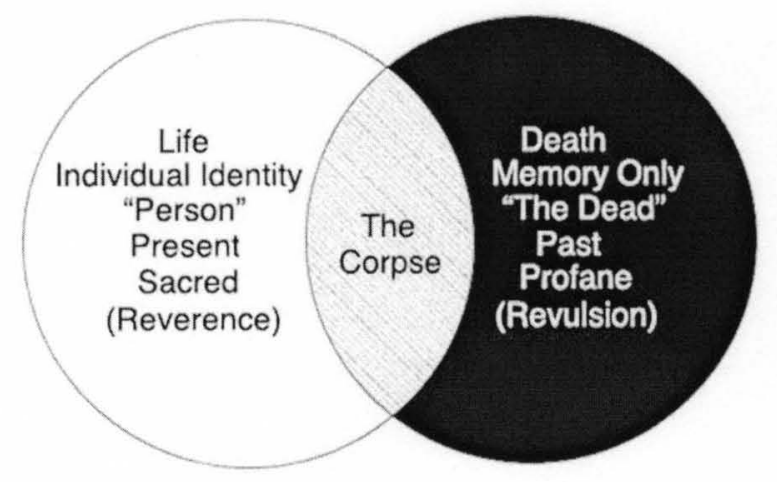

Fig. 2: The Corpse as a Liminal Object in Symbolic Systems 
The "crucial moment of hesitation" on the part of the anatomist signifies both the moment of Craig's abandoning of scientific detachment to metaphorically induced empathy and the time just before Taussig's ship's disembarks from the shore of the living. The corpse is that ship, just as the painting is, as well. 


\section{CHAPTER III}

\section{THE TRADITIONAL ELEGY}

\section{Something it is which thou hast lost... \\ - Alfred Tennyson "In Memoriam"}

In literature, the dead have traditionally been grieved and commemorated in several specific forms, most notably the eulogy and the elegy. These forms help the bereaved by dictating and containing the act of grief within their structures. Like all rituals of death seen cross-culturally, the poetic and literary "rites" contained in the elegy and eulogy forms help to move listeners and readers through a comforting process that helps to give meaning and completion to the dead.

Though the elegy form has been in existence since at least the time of Ancient Greece (and likely much longer), the Western tradition from which contemporary poets operate has its roots in the $19^{\text {th }}$ century romanticism. As Gloria K. Fiero states: "One of the central features of nineteenth-century romanticism was its love affair with nature and the natural world. Aesthetically, they perceived in nature, with all its shifting moods and rhythms, a metaphor for the sublime: the power and mystery of forces that inspire awe, solace, and self-discovery" (3). Further, "romantics perceived the turbulent mysteries of nature as the wellspring of the sublime; many even viewed God and the natural universe as one" (3). This view, known as pantheism, would permeate the poetry of this period, and its elegy forms. Fiero states that the romantic poet John Keats saw poetry and art as "more than a response to the human experience of love and nature... [but rather] a higher 
form of nature that triumphantly outreaches the mortal lifespan" (7). This is shown with particular clarity in his poem "Ode to a Grecian Urn," for example: "Ah, happy, happy boughs! that cannot shed/ Your leaves, nor ever bid the Spring adieu;/ And, happy melodist, unwearied,/ For ever piping songs for ever new..." (Fiero 8).

The serene contemplation of nature and its solace can also be seen in the visual arts from this time period, especially in the paintings of John Constable. In "The Haywain," painted in 1821, the human figure in a wagon fording a river is diminished in the face of the wide swath of English countryside and sky (Fiero 11). If the viewer is to contemplate anything in this painting, it is that field, those trees, and that sky. It is not the issues of the person, his duties, his troubles, or other details of his life. What is divine, what lasts, is in the landscape, in nature itself.

From this come the elegies of the time. Look at Matthew Arnold's "Dover Beach," for example. Here, lamenting the loss of faith in God, Arnold writes this elegy of faith:

The sea is calm to-night.

The tide is full, the moon lies fair

Upon the straits; on the French coast the light

Gleams and is gone; the cliffs of England stand;

Glimmering and vast, out in the tranquil bay....

The Sea of Faith

Was once, too, at the full, and round earth's shore

Lay like the folds of a bright girdle furled. 
But now I only hear

Its melancholy, long, withdrawing roar,

Retreating, to the breath

Of the night-wind, down the vast edges drear

And naked shingles of the world.... (Arnold)

Faith in God may have diminished, but for Arnold (who was deeply religious), the "cliffs of England" stand.

Elegies have a pattern to their movements, a sort of psychological ritual or "work." In The English Elegy, Peter Sacks compares the elegy and its conventions to what Freud called "the work of mourning" (1). By this, Sacks comes to the interesting conclusion that elegies are themselves made up of literary interpretations of social and psychological mourning practices. An excellent example of this is the traditional custom of mourners writing elegies for the dead and tacking them up on the sides of the funeral hearse, almost as though the living are somehow compelled to make a physical, paper barrier between themselves and the dead. This is done to emphasize the livings' own surviving power, and it interposes a little ease for the living: "...the funeral flowers, like the poetic language to which they are so often compared, serve not only as offerings or as gestures for respite but also as demarcations separating the living from the dead" (Sacks 19-20). Words, poems, immediately become for the mourner more than their physical representations on the page; they instead transform into several replacements for the dead, what Sacks describes as "a fabric of language...that may cover the preceding lack caused by the loss of the dead" (Sacks 18). This is but one of the many conventions that 
Sacks details in his work, the use of language, of poetry in particular, to help the mourner do his or her Freudian "work."

The other conventions are embedded in elegies as far back as Theocritus's "First Idyll," which was perhaps the first elegy. These conventions include the pastoral contexualization, which, as noted above, was a cornerstone of the elegiac works of romantics such as Keats and Arnold. Elegies also include the use of repetitions and refrains. These continual uses of language move against the obvious discontinuity of death. Elegies also feature reiterated questioning and sudden, forceful outbreaks of anger or cursing by the speaker. These poems will also deal with recurrent themes such as the use of traditional images of resurrection and rebirth, echoes of myth and mythic figures, particularly the vegetative god or goddess, who is an immortal, earth-bound figure usually associated with the changing of the seasons. These figures, Sacks argues, in fact replace the dead for the poet, thus substituting the all-too-human figure with a symbolic, immortal figure of power (19).

Note the movements of many of the motifs in William Collins' 1749 elegy "Ode on the Death of Mr. Thomson," here included in its entirety. From the direct address of the deceased to the pastoral imagery of the English countryside to references to the changes of the seasons, the poem clearly marks itself in the line the traditional elegy form:

Im yonder grave a Druid lies, Where slowly winds the stealing wave!;

The year's best sweets shall duteous rise, To deck its Poet's sylvan grave! 
In yon deep bed of whispering reeds

His airy harp shall now be laid;

That he whose heart in sorrow bleeds

May love through life the soothing shade.

Then maids and youths shall linger here;

And, while its sounds at distance swell,

Shall sadly seem in Pity's ear

To hear the woodland pilgrim's knell.

Remembrance oft shall haunt the shore,

When Thames in summer wreaths is drest;

And oft suspend the dashing oar,

To bid his gentle spirit rest!

And, oft as ease and health retire

To breezy lawn, or forest deep,

The friend shall view yon whitening spire,

And, 'mid the varied landscape weep.

But thou who own'st that earthly bed,

Ah! what will every dirge avail!

Or tears which Love and Pity shed, 
That mourn beneath the gliding sail!

Yet lives there one whose heedless eye

Shall scorn thy pale shrine glimmering near!

With him, sweet Bard, may fancy die;

And Joy desert the blooming year.

But thou, lorn stream, whose sullen tide

No sedge-crown'd sister now attend,

Now waft me from the green hill's side

Whose cold turf hides the buried friend!

And see the fairy valleys fade;

Dun Night has veil'd the solemn view!

Yet once again, dear parted shade,

Meek Nature's Child, again adieu!

The genial meads, assign'd to bless

Thy life, shall mourn thy early doom;

Their hinds and shepherd-girls shall dress,

With simple hands, thy rural tomb.

Long, long thy stone and pointed clay 
Shall melt the musing Briton's eyes;

O! vales and wild woods, shall he say

In yonder grave your Druid lies! (Collins) 


\section{CHAPTER IV}

\section{"THE GOOD DEATH" AND THE ROOTS OF MODERN DESACRALIZATION}

\section{.... if I have to die on the battlefield, if some kind friend would just lay my Bible under my head and your likeness on my breast with the golden curls of your hair, that it would be enough.}

- Civil War soldier William Stilwell, to his wife Molly

Now, let us move away from this theoretical and literary discussion and look at the historical shift in the metaphorical and cultural meanings of death, liminality, and the corpse.

Events of the late- $19^{\text {th }}$ and early $20^{\text {th }}$ century, particularly mass conflicts such as the U.S. Civil War, disrupted the traditional meanings of the individual's death. These traditional meanings can be summarized under the concept of "The Good Death," a series of agreed-upon ritual components of what constituted a kind of death that gave the life of the individual and his or her life true meaning.

According to historian Drew Gilpin Faust, "dying was an art...to mid-nineteenthcentury Americans, as it has long been at the core of Christian practices" since at least the fifteenth century (Faust 6). Jeremy Taylor's The Rule and Exercise of Holy Dying, written in 1651, translated the Catholic rituals known as ars moriendi into Protestantism and formed the basis of how to go about practicing this "art" (6). To die a Good Death, one should: 
...die among family assembled around the deathbed. Relatives would of course be most likely to show concern about the comfort and needs of their dying loved one, but this ultimately is a secondary consideration. Far more important, family members needed to witness a death in order to assess the state of the dying person's soul, for these critical last moments of life would epitomize his or her spiritual condition.... Kin would use their observations of the deathbed to evaluate the family's chances for reunion in heaven. (Faust 10)

Faust goes on to sum up the ritual by saying that "a life was a narrative that could only be incomplete without this final chapter, without the life-defining last words" (10).

Historian Mark S. Schantz adds that these last words would act as a "spiritual lesson" for those who were left behind, creating a sort of "temporal chain" as life ended (18-19). After this ritual, the body was given a proper and very individualized burial, with the corpse visited for a period of time in a vigil, then commemorated in a religious ritual. Eulogies were given to celebrate the life, to provide comfort on the departed soul's disposition, and to offer instruction about the meaning of death.

But during the Civil War, as with the Mexican-American War, Americans witnessed people dying away from home, in vast numbers and in ways that didn't even allow the bodies to be buried properly. In all, approximately 620,000 soldiers died between 1861 and 1865 , a number that is roughly "equal to the total American fatalities in the Revolution, the War of 1812, the Mexican War, the Spanish-American War, World War I, World War II, and the Korean War combined" (Faust xi). Dealing with this massive number of casualties was thus beyond the culture's experience. For example, in just one battle, the battle of Gettysburg, "an estimated six million pounds of human and animal 
carcasses lay strewn across the field in the [July] heat..." (Faust 69). The last of the bodies weren't even put in the ground until October, necessitating that people walk around with bottles of pennyroyal and peppermint oils on rags to lessen the effects of the odor of decay (69).

Some tried to replace the rituals of The Good Death with letters; others tried using the newly developed process of embalming, the burgeoning funeral industry's answer to prolonging the "life" of the corpse to allow for its transport back to home and family and proper ritual burial. But this cost more than most Americans could afford at that time, and sometimes was not even possible given the limited availability (and reliability) of the technology and its practitioners. Others turned to another new invention, photography, but access to it was likewise limited.

Most were left with nothing - no souvenirs, no photos, no letters, no news, no body. As a result, a rupture formed in the sacredness of death as individuals, families, and communities had to revise how to memorialize those who died far from home and whose corpses could not be mourned directly. This had a profound impact on the rituals and writings surrounding death. ${ }^{2}$

And modern warfare was just getting started with its tampering with the concept of what it meant to die well. In the next section, we will see how the $20^{\text {th }}$ century and its cycle of conflicts would call into question even death for country in war, and with it the meanings of death and the body themselves.

\footnotetext{
${ }^{2}$ As an interesting side note, after the defeat of the South, the bodies of the Northern dead were buried and sometimes exhumed for proper burial in national cemeteries. However, the bodies of Southern dead were often left in the open or their exhumation forbidden under penalty of death. Faust and other historians believe this mistreatment of the dead and their persistence on the landscape of the fields and towns of the South gave rise of the Confederate "pride" movement that still persists today, since in defeat the sacrifice of these dead was given the ultimate disruption of The Good Death, and the people had to find new ways to make meaning for the generation's loss (Faust 240-241).
} 


\title{
CHAPTER V
}

\author{
WAR IN THE $20^{\text {th }}$ CENTURY: THE DEATH OF DULCE ET DECORUM EST... \\ Cultivate a taste for distasteful truths. And...most important of all, endeavor \\ to see things as they are, not as they ought to be. \\ - Ambrose Bierce
}

To win battles, you do not beat weapons-you beat the soul of man, of the enemy man. - General George S. Patton, to his son on D-Day

"Dulce et decorum est pro patria mori," writes the Roman lyric poet Horace in the Odes, and despite the disruptions in the traditional practices of mourning, the men who took up arms in the North and the South in the U.S. Civil War still had this sentiment as the foundation for their willingness to die for their chosen country. Roughly translated as "It is sweet and fitting to die for the homeland," it had likewise been the motto of men going to war and of governments and leaders who asked these men to do so since ancient times. The motto lived beneath the life and work of Walt Whitman, the great poet of the U.S. Civil War, who celebrated the dead in such poems as "A Sight in the Camp in the Daybreak Gray and Dim." A medic during the war, Whitman wrote the poem after exiting a hospital tent at dawn and seeing three draped corpses lying near the tent's entrance.

Curious I halt and silent stand,

Then with light fingers I from the face of the nearest the first just lift the blanket;

Who are you elderly man so gaunt and grim, with well-gray'd hair, 
and flesh all sunken about the eyes?

Who are you my dear comrade?

Then to the second I step--and who are you my child and darling?

Who are you sweet boy with cheeks yet blooming?

Then to the third--a face nor child nor old, very calm, as of

beautiful yellow-white ivory;

Young man I think I know you--I think this face is the face of the

Christ himself,

Dead and divine and brother of all, and here again he lies. (Whitman)

Even in their anonymity, the men are beautiful to Whitman, particularly the final figure, whom Whitman likens to Christ himself, the nameless, nearly ageless soldier transformed into a new martyr for the nation's cause of redemption. In another poem, "The Artilleryman's Vision," a veteran, now home from the war, dreams of combat:

The engagement opens there and then in fantasy unreal, The skirmishers begin, they crawl cautiously ahead, I hear the irregular snap! snap!

I hear the sounds of the different missiles, the short t-h-t! t-h-t!

of the rifle-balls,

I see the shells exploding leaving small white clouds, I hear the great shells shrieking as they pass,

The grape like the hum and whirr of wind through the trees, (tumultuous now the contest rages,)

All the scenes at the batteries rise in detail before me again, 
The crashing and smoking, the pride of the men in their pieces....

(The falling, dying, I heed not, the wounded dripping and red heed not, some to the rear are hobbling,)

Grime, heat, rush, aide-de-camps galloping by or on a full run, With the patter of small arms, the warning s-s-t of the rifles, (these in my vision I hear or see).... (Whitman)

Note Whitman's details: The men blown to pieces by the artillery are said to be "proud," and in his memory, the artillery man shows no ill effects from being part of the battle. He does not "heed" the dead or dying. Instead, he remembers only the glory of the battle. This is similar to the sentiment of Henry, the youth in Stephen Crane's 1895 novel The Red Badge of Courage. Here, as the battle is won and Henry begins the walk from it with his comrades, he thinks this:

Regarding his procession of memory he felt gleeful and unregretting, for in it his public deeds were paraded in great and shining prominence. Those performances which had been witnessed by his fellows marched now in wide purple and gold, having various deflections. They went gayly with music. It was pleasure to watch these things. He spent delightful minutes viewing the gilded images of memory. He saw that he was good. (Crane)

These are the rewards of war for a just cause and the prize for taking part. No regrets, no trauma, a Christ-like sense of sacrifice, a coming-of-age into a noble kind of manly maturity that only war can bestow on youth. Horace's "sweet and fitting" death is still very much in command of this fight. "The Good Death" is, even at the time of these writings, being disrupted, but the ripples of this disruption have not yet reached the men 
on the field. It would take decades — and another war on the other side of the world—for the disruption of this "good," sweet, and fitting death to be complete.

The First World War was a strange conflict on a number of levels. First, rather than being a war fought for one's home country, it was fought not for nation but for politics, based on a "complex system of European alliances, negotiated over decades" (Fussell 30). In this dispute between Austria-Hungary and Serbia, which began in June of 1914 with assassination of Archduke Francis Ferdinand in Sarajavo, Russia allied itself with Serbia, while Germany honored an age-old alliance with Austria-Hungary. Because of a treaty with Russia, France was pressed into service to help that country in the fight, and a Britain moved into the fight because of a treaty with France (30). This is a far cry from the immediate conflicts of the U.S. Civil War, where battles were raging on one's own farm or in one's own state, with family and country directly at stake. This meant that the men of this war would, to a great extent, fight in some distant land for the honor of treaty and for a country to which they had no direct affiliation. The idea of "one's country" was becoming a vague concept for which it would be "sweet and fitting" to lay down one's life.

In England, Germany, and the other countries involved in World War I, young men of the upper class joined the military as though they were going on some grand adventure, a generation at last having a chance to fight a noble war as their elders had done. One soldier, C.E. Montague, described how "all the air was ringing with rousing assurances...freedom and civilization rewon, a sour, spoiled, crooked old world to be rid of the crooks and reclaimed for straightness, decency, good nature. What a chance!" (qtd 
in Fussell 30). Among the lower class, there were many many conscripts, men with no means who were sent to the trenches of Belgium and France by the thousands.

It did not take long for all involved to realize that this "chance" that Montague spoke of was not another in the long line of the dignified, noble conflicts of the nation's history. Technology in the form of tanks, artillery, machine guns, and gas had made traditional methods of fighting obsolete, taking away a seemingly vital personal element of warfare. No longer would two men or two armies meet face to face, mettle to mettle, on the field of battle. In fact, the vast majority of the men killed in the trenches would never see the person responsible for their death from the random shell, the gas canister fired, the machine gun hidden in its nest. The men were rotated amongst three trenches, a forward that saw the majority of the fighting and took the most casualties, a middle that acted as a repository of supplies, and a rear trench for men resting and-more and more frequently-for officers intent on protecting their own hide. The men could not advance. A typical day in the forward trench was spent dreading gas and artillery and little else. At night they reinforced or extended the trench. Three weeks of this and they were rotated to the rear for rest until it was time for them to start the cycle again (Fussell 30-35).

Meanwhile, in the middle of the two lines of trenches, the infamous "No Man's Land" stretched, covered with corpses, so many in fact that the military was forced to publish regulations entitled Treatment of Bodies Exposed in the Open which cannot be Buried or Cremated. It begins: "Bodies in a state of putrification lying out in advance of the trenches which cannot be buried or cremated owing to hostile fire, or bodies uncovered in parapets of trenches where they have been hastily buried, often give rise to 
considerable nuisance" (qtd in Fussell 32). Whitman's Christ-like casualties, individually mourned, are now reduced to realm of "nuisance."

Despite the British gnat-like nicety of the term, "nuisance" is indicative of what would become a trend in modern literature of war. As Paul Fussell writes, "One repeated motif in modern war writing...is the disclosure of the unpleasant actuality lurking beneath such popular euphemisms as casualty, traumatic amputation, pacification, combat fatigue (madness), and collective indiscipline (mutiny)" (23). By World War I, the writers who went to war-and there were many, as so many lettered men in Great Britain went—would become the antithesis of Whitman's artillery man and would tell in excruciating detail what war really is.

Horace's saying became known as "The Old Lie," though there were some writers who continued to try to tell it, to believe it. In "Epitaph on an Army of Mercenaries," A.E. Housman speaks of professional British soldiers killed in the first months of war: "Their shoulders held the sky suspended;/ They stood, and earth's foundations stay;/ What God abandoned, these defended,/ And saved the sum of things for pay" (Housman 71). Poet Hugh MacDiarmid (pen name for Scottish nationalist Christopher M. Grieve) replied with his own poem "Another Epitaph on an Army of Mercenaries:"

It is a God-damned lie to say that these

Saved, or knew, anything worth any man's pride.

They were professional murderers and they took

Their blood money and impious risks and died.

In spite of all their kind some elements of worth

With difficulty persist here and there on earth. (MacDiarmid 313) 
But it is Wilfred Owen who most directly indicts the "Old Lie" in his poem "Dulce et Decorum Est." The poem, a stark, gruesome description of a gas attack, has the poet focus his attention on one young man killed by the attack, one that haunts Owen in "all his dreams."

If in some smothering dreams you too could pace

Behind the wagon that we flung him in,

And watch the white eyes writing in his face,

His hanging face, like a devil's sick of sin,

If you could hear, at every jolt, the blood

Come gargling from the froth-corrupted lungs...

My friend, you would not tell with such high zest

To children ardent for some desperate glory,

The old Lie: Dulce et decorum est

Pro patria mori. (Owen 66)

By World War II, the poets were left with little to say that had not been said, and the literature reflected the dogged determination of the world as it took on Hitler and Germany's advance. "This is where we came in; this has happened before/ Only the last time there was cheering," Canadian poet Milton Acorn said, seeming to sum up the sentiments of most of the writers of the time (Fussell 311). But there was a larger problem at well - death during World War II had reached levels that were beyond the realm of human understanding on many levels. First, there were the civilian casualties, innocent people who were killed, often purposefully, by the millions in clear violations of the codes of war. Then there was the sheer magnitude of the numbers of people involved 
in and killed or wounded in battle, as in the Battle of Kursk in the Soviet Union, which involved more than two million men in a single battle. The Holocaust--both in the sheer numbers of those killed for no reason other than the fact that they were Jewish, or gypsies, or homosexuals, or political dissidents-remains one of the great incomprehensible moments in modern history. In all, 78 million people were killed or wounded during the conflict (Fussell 307).

"God is dead. He remains dead. And we have killed him," Nietzsche wrote in The Gay Science just prior to the start of the $20^{\text {th }}$ century, and with modern warfare, the culture had killed the nobility of war and of dying for a cause, as well, replacing cause with the muddiness of politics and political gain. Writers continued to take on war, but as modernity turned its attention to the individual, as cultural structures fell into doubt or gave way, the writers too turned not to the individual, and there is nothing quite as stark as the experience of war from that vantage point. Add to this bleak view wars such as that fought in Vietnam, in which Western writers could not even look on victory as a way to make meaning of the experience, and the honorable view of death in combat is reduced again: We see this in this excerpt from Vietnam veteran Bruce Weigl's poem "Song of Napalm:"

Still I close my eyes and see the girl

Running from her village, napalm

Stuck to her dress like jelly,

Her hands reaching for the no one

Who waits in waves of heat before her. 
So I can keep on living,

So I can stay here beside you,

I try to imagine she runs down the road and wings

Beat inside her until she rises

Above the stinking jungle and her pain

Eases, and your pain, and mine.

But the lie swings back again.

The lie works only as long as it takes to speak

And the girl runs only as far

As the napalm allows... (Weigl)

And the loss of the meaning of death in war is still mourned even today, as seen in the 2003 poem "The Hurt Locker," written by poet Brian Turner, who fought in the war in Iraq: "Nothing but hurt left here./ Nothing but bullets and pain/ and bled-out slumping/ and all the fucks and goddamns/and Jesus Christs of the wounded./ Nothing left here but the hurt" (Turner 11).

The problem is this: if war loses its sense of "cause," of purpose, war is simply killing and dying. Worse, it is killing and dying often by coercion, for no reason, and in the name of risk without reward. It is another rite in the long list of rites that has lost its sacred space. The dead hero, the martyr, loses his place of transcendence if he loses his 
higher calling because without a quest, there is no hero. He becomes "casualty," his remains a "nuisance," his identity absorbed into these words along with the millions. This is the legacy of modern war, and it is from here that Western culture witnesses a fundamental shift of what it means for a person to die, what it means to commemorate the dead, and what can be commemorated in an effort to give loss and grief and these cultural changes meaning. The invention of photography played a large role in spurring these changes, as we will see in the next chapter, and with its invention and application to death in war, these radical shifts in the contemporary meaning of death and mourning truly begin. 


\section{CHAPTER VI}

\section{THE FROZEN FRAME}

\section{A camera is a tool for learning how to see without a camera. \\ - Dorothea Lange, photographer}
No one will ever know what I went through to secure those negatives. The world can never appreciate it. It changed the whole course of my life.
- Mathew B. Brady

The use of photography to capture images of actual corpses began in the Victorian Age, nearly immediately after the technology to do so was developed. One of the most popular choices of subject for these early death photographs were pictures of infants and children, as shown in Fig. 3. Because the children had not been able to accomplish anything in their short lives, nor were they able to impart any wisdom or understanding of their lives or the disposition of their souls, the photograph became a replacement for the children's lives in Schantz's "temporal chain." Often these photos - often called "Sleeping Beauties" or "Sleeping Angels" -- were the only evidence the parents would ever have that the child had ever existed at all. 


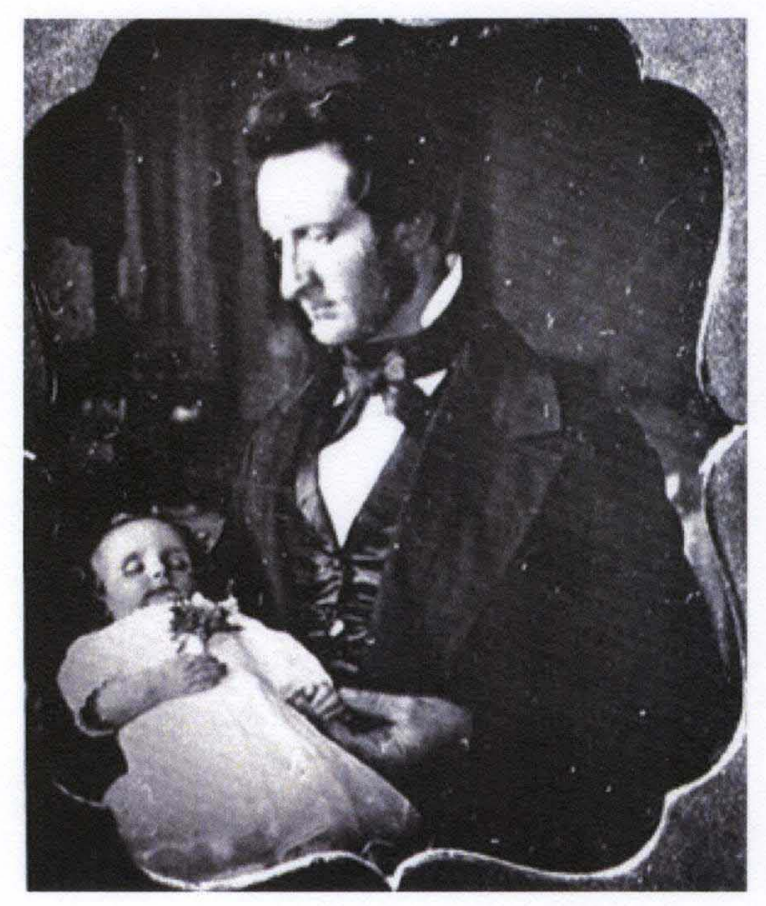

Fig. 3: Anonymous, "Victorian Post Mortem Photograph," http://www.estatevaults.com/lm/\%20\%20Victorian\%20post\%20mortem\%20photos-1.jpg

The Civil War marks the first time photography was used to document war, and some of the most familiar images of the Civil War came from the photographic eye of Mathew B. Brady, a jewelry-case manufacturer turned photographer who had his own photography studio in New York by 1844 (Library of Congress). One of America's bestknown portrait photographers of the age, Brady turned his attention to the Civil War when it broke out in 1861. More of a project manager than an individual photographer, Brady oversaw a group of photographers who took the actual battlefield photos. He processed and kept their negatives, as well as those he purchased from amateur photographers just back from the battlefields. Regardless of whether he took them himself, oversaw their development, or purchased them, all of the photos Brady dealt with from the war are marked "Photograph by Brady" (LOC). Though there is some 
controversy as to whether Brady's photos were actual battlefield scenes or if they were staged for dramatic effect, the impact of these first photo-documentaries of war

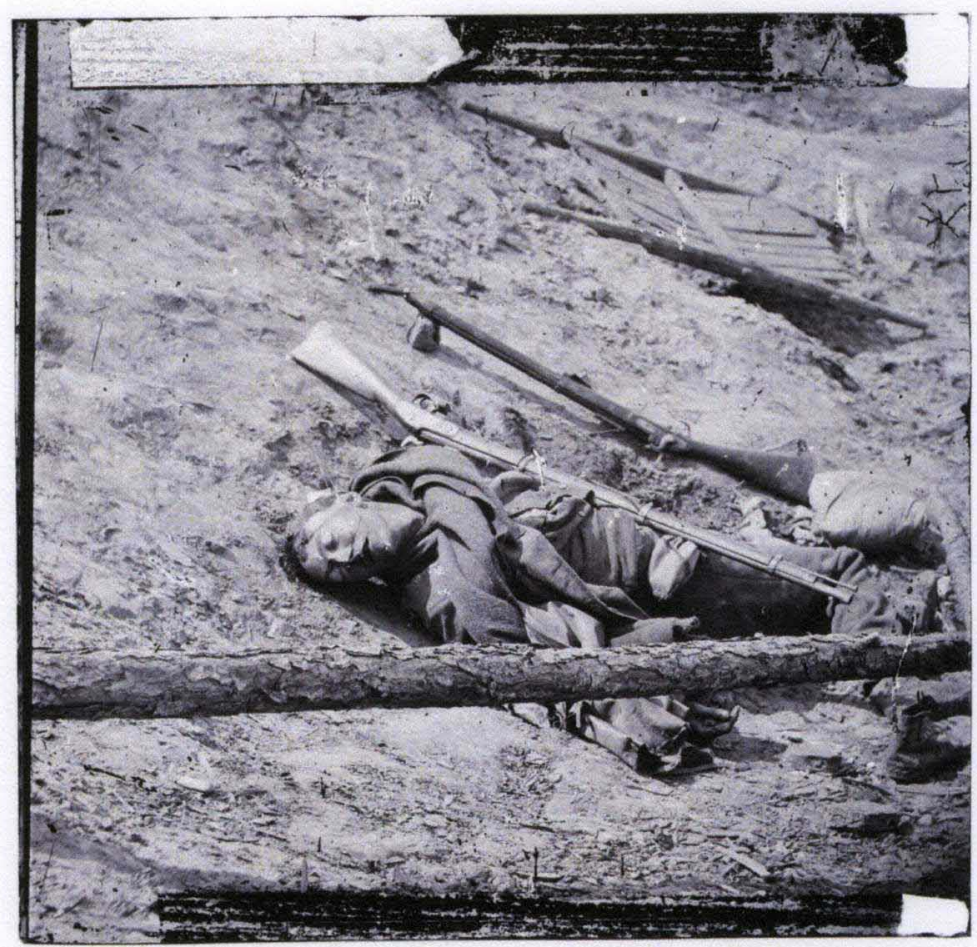

Fig. 4: Mathew B. Brady, "Dead Confederate Soldier, Petersburg, 1865," http://www.civilwar.net/cw_images/files/images/695.jpg

still resonates, as is in Fig. 4, titled simply "Dead Confederate Soldier, Petersburg, 1865:" Issues of authorship, staging, accuracy of date or location all become irrelevant in the face of such an image. A pre-teenage boy dead on a battlefield transmits an authentic emotional experience of the grief of war. The rest falls away.

A second image projects the helplessness, the loneliness of the battlefield death. In "Confederate Dead, Spotsylvania Country Courthouse, 1865" (Fig. 5), the man is robbed of not only his life but his individual identity, even the photo's caption lumping 
him into the anonymity of the mass dead. Note how his arms are raised in the defenseless posture, the piling of weapons and personal belongings gathered around him:

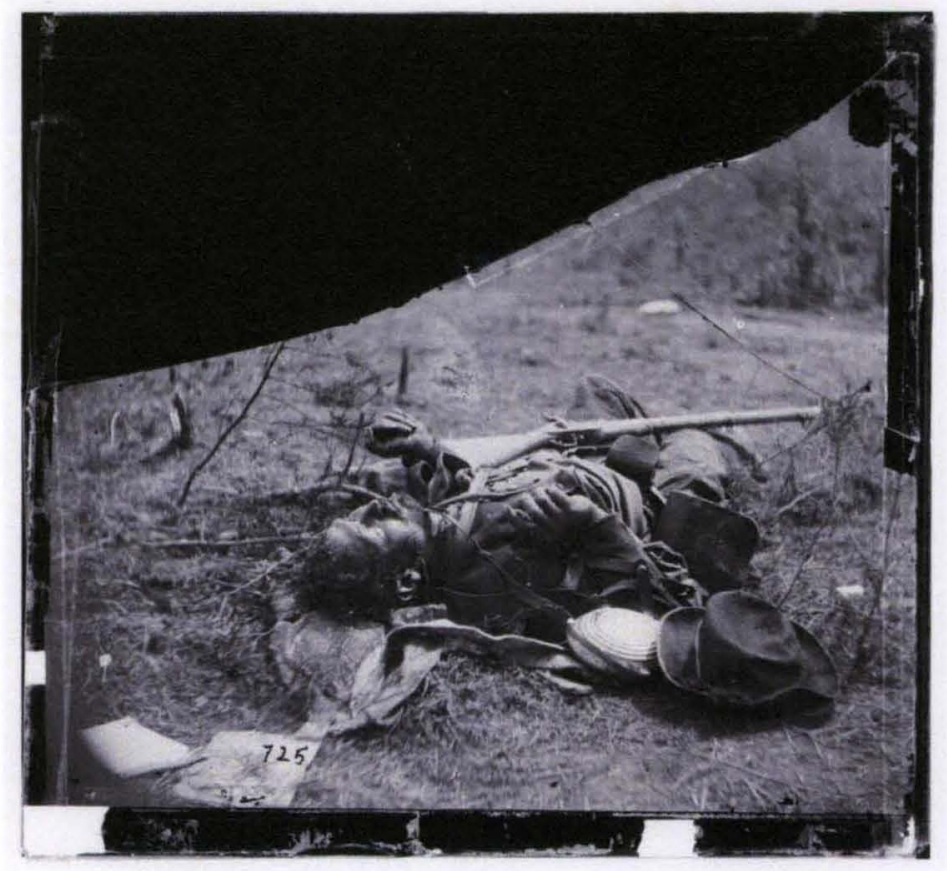

Fig. 5: Mathew B. Brady, "Confederate Dead, Spotsylvania County Courthouse, 1865," http://faculty.smu.edu/sweisenb/Conf\%20Dead\%20Spotsylvania\%20Cthse.gif

In 1862, Brady opened the first exhibit of war photography in New York at his studio. Because the battles of the Civil War tended to take place in rural areas, on farms and countrysides or small towns, most Americans had never experienced the horrors of the battlefield first-hand. Thus, Brady's exhibit, "The Dead of Antietam," marked the "first time most people witnessed the carnage of war" (LOC). A reporter with The New York Times wrote on seeing the exhibit: "Brady [has] brought home to us the terrible reality and earnestness of war" (LOC).

The exhibit was perhaps too much, in fact. After the war ended, the American public found it had no stomach for viewing Brady's images, and he lost everything to financial ruin as the market for and interest in his photos dried up (LOC). But his 
photographs had done an important work, as had Brady himself, by bringing home the reality of the terrible conflict and commemorating the loss, even if only through representatives and representation, of the thousands of unnamed and unburied dead.

As stated earlier, Brady's photos have lost little of their impact, even as war and war photography have progressed into the contemporary age. There is a terrible stillness to them that is deeply affecting to the viewer, a timeless and somehow familiar quality in how they are able to depict death. This is so because the photographs operate from fundamental theories of photography and their effects on the viewer explored in the work of French philosopher Roland Barthes.

Roland Barthes is himself difficult to fit neatly into a category. Made up of equal parts of philosopher, poet, scholar, social scientist, linguist and critic, he himself felt the confines of the narrow tract he traversed between positivism and interpretation:

[I am] the subject torn between two languages, one expressive, the other critical; and at the heart of this critical language, between several discourses, those of sociology, of semiology, and of psychoanalysis - but [I tell myself] that, by ultimate dissatisfaction with all of them, I was bearing witness to the only sure thing that was in me...: a desperate resistance to any reductive system... I began to speak differently. (Barthes 8)

Barthes seems to find this new language for science and art in his book Camera Lucida, making plain that it is the language of theory that is solely capable of moving between the shores of science and art. 
Any summation of Camera Lucida cannot do justice to the elegance of both Barthes' language and logic, but it does aid this discussion of liminality to review Barthes' key concepts on photography's content and implied intent.

"A specific photograph...is never distinguished from its referent (from what it represents)..." Barthes writes early in the book (5). He goes on to curiously invoke Bronfen's association of corpses and beauty when he says that "It is as if the Photograph always carries its referent with itself, both affected by the same amorous or funereal immobility...they are glued together, limb by limb, like the condemned man and the corpse in certain tortures; or even like those pairs of fish...which navigate in convoy, as though united in eternal coitus" (Barthes 5-6). The overlapping of the categories - the actual photograph and its subject or content - is already beginning in Barthes' discussion, a blurring he takes even further when he points out that "...a photograph is always invisible: it is not it that we see" (6). This explains why, when people share photos with one another, they do not typically offer the photo by saying: "This is a photograph of my son," but rather with the simple descriptor, "this is my son." The fused quality of the photo and referent is contained in that simple phrase.

It is also useful to review Barthes' determinants for the three parts of a photograph, both because they help in giving a common language to the analysis of all photos, and because it is with these names that Barthes begins to discuss the way that photographs become signifiers of death.

The Operator is the Photographer. The Spectator is ourselves, all of us who glance through collections of photographs - in magazines and newspapers, in books, albums, archives. . . And the person or thing photographed is the target, the 
referent, a kind of little simulacrum, an eidolon emitted by the object, which I should like to call the Spectrum of the Photograph, because this word retains, through its root, a relation to "spectacle" and adds to it that rather terrible thing which there is in every photograph: the return of the dead. (Barthes 9) A photograph that interests the Spectator does so because it advenes (from "advenience"), a word that implies that the photograph has taken the viewer on some "adventure" on viewing it (Barthes 19). Though the photograph is by no means in motion, it still retains the quality of animation, though what it animates - makes alive - is not the referent but the Spectator: "The photograph itself is in no way animated...but it animates me: this is what creates every adventure" (Barthes 20).

Two other terms are important to note: studium and punctum. The studium can be described as what we bring to the photograph and its field. It is, for example, the knowledge of history or political structures depicted in a photograph, familiarity with a specific geographical place, or information we bring to a photo of a familiar person. The punctum, "sting, speck, little hole," is what interrupts the studium, that aspect that "shoots out of [the studium] like an arrow" and "pierces" the Spectator (Barthes 26). "A photograph's punctum," Barthes concludes, "is that accident which pricks me (but also bruises me, is poignant to me) (27). It is the focal point for the Spectator, though the specific aspect of the photograph that "pricks" often varies according to what animates or "advenes."

Barthes finds the moment when the photograph becomes death most succinctly when he views photographs of himself. When Barthes confronts self-portraits, he sees in the picture's field "that very subtle moment when, to tell the truth, I am neither subject or 
object but a subject who feels he is becoming an object: I then experience a microversion of death (of parenthesis): I am truly becoming a specter" (Barthes 14).

Thus, even the living referent can only see himself as object - as a corpse, suspended somewhere between past and present, between Self and Other (the ones who will view the photograph and come to some conclusion about the Self from it), the living and the dead. "The Photographer knows this very well, and himself fears (if only for commercial reasons) this death in which this gesture [of the Photography] will embalm me...I have become Total-Image, which is to say, Death in person" (Barthes 14-15). This is why many find viewing photographs of themselves uncomfortable or strange. The living person they sense themselves to be cannot be found there in that dead place, any more than the living person that a photograph of a dead person holds can be sought out on the living world. Like the corpse, like Taussig's "ship of the dead," one can view the referent in the stillness of the photo, but it is not here on the living's shore.

If we revisit Figure 2, the overlapped area containing "The Corpse" can be revised and labeled with "The Photograph" and the significations meeting in that overlapped space remain the same. The photograph becomes the threshold between life and death. It is, in fact, that liminal space the photograph wishes to capture or "take." The more liminal an object's nature between categories, as we have seen through Douglas and Leach, the more taboo and sacred it becomes, the more, to quote Barthes, it has the potential to "advene." Thus, photographs of literal death layer categories of liminality and its sacred connotations so effectively that even without the presence of a physical corpse, the photo's studium becomes the "ship of the dead," its stillness, like the corpse's, the source of its "amazing capacity for travel," to animate, though it is the Spectator, and, 
as we will see, his or her perception of the physical space contained in the studium that "animates" (Taussig 103; Barthes 20). 


\section{CHAPTER VII}

\section{THE DECLINE OF THE CORPSE'S SACRED CULTURAL SPACE}

\section{Nothing has taught me more about light than being in the dark. - Josh Lehrer, photographer}

From here, we return to Corpse Theory to explore a fundamental shift in the meaning of the sacred space created by the corpse in its liminal state. Now that we have established that the photograph is also able to hold and impart this liminality for the viewer, we will look at how this medium is able to capture and freeze a shift in cultural attitudes about death and the dead.

If a photograph can become a liminal space, and a photograph of the dead themselves doubles and redoubles this liminal state, photographs partly advene because they help to create this sacred, taboo space. But can photographs have the opposite effect? Is it possible that using the dead as the subject of photography can actually diminish the sacredness of the dead, and of death itself? And if the sacred nature of death and its rituals change, how then can we properly commemorate them and give their lives—and our own as the surviving power-meaning?

To answer these questions, we must return to painting, specifically to one painting, Rembrandt's 1632 painting "The Anatomy Lesson of Dr. Nicholaes Tulp" (Fig. 6). Here, Dr. Tulp, a member of the Guild of Surgeons in Amsterdam, is using a cadaver to teach other Guild surgeons about anatomy through a public dissection of this corpse. 
These are clearly upper class men, as evidenced by their dress. The faint background, from which the surgeons and the body are "emerging," shows this to be an operating theatre.

According to critic William S. Heckscher, the corpse in the painting - a thief named Adriaan Adriaanszoon (a.k.a. Aris Kindt), has been dead less than 36 hours

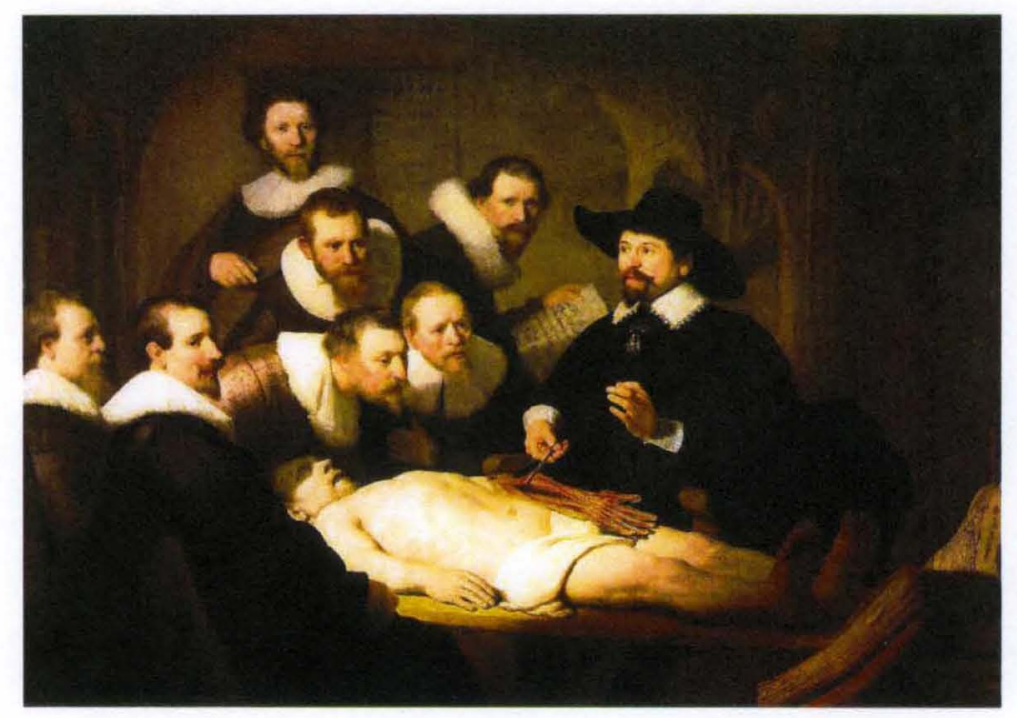

Fig. 6: Rembrandt von Rijn, "The Anatomy Lesson of Dr. Nicholaes Tulp," http://www.commed.uchc.edu/medicalhumanities/images/art/rembrant_anatomy_lg.gif

at the time of the dissection, put to death for his crimes by the state $(36,131)$. This annual public dissection took place before an audience who had purchased tickets for the event, whose vantage point matches that of the painting's viewers. Tulp has raised the criminal's left hand and dissected it first, a breech of usual dissection practice, which mandates opening the body first. In this way, as literary theorist Francis Barker states, "if the hand of a thief, as the offending member, would receive the special attention of the executioner, no less does it here receive the first ministrations of the anatomist..." (66). Barker goes further to say that "the scene of dissection is thus an exercise of the 
jurisdiction over the body of Aris Kindt, an act of penal and sovereign domination which is exemplary and substantive, symbolic and material, at the same time" (67). Thus, this is a scene of corporal punishment, with the opening of Kindt's body for public "consumption" acting as an extension of the punishment the state has set for his crimes. So while we might look to changes in the sacred nature of death through the use of photography, this painting shows that a shift is going on in the meaning of death and the corpse much earlier than the Civil War and Mathew B. Brady's work. The subjectivity of this painting shows it as a turning point in cultural attitudes about death. For example, note how Rembrandt has depicted the surgeons' gaze in the painting. None of them, not even Tulp himself, is looking at the body. They are either focused on the viewers (alive), or they are looking at the anatomy textbook. According to Barker, “...that they do not see the flesh...only further emphasizes the extraordinary historical contortion by which the body on display has become in an important sense invisible" (70). Here, the circumstances of death are prescribed and controlled by the living, and the humanity of the body vanishes into the realm of object or text.

To return to photography, to a war only a few decades after the subject of Mathew B. Brady's work, the work of Robert Capa shows a shift in photography's "role" in commemorating death and its liminal sacred space. Capa followed in Brady's footsteps in terms of using photography to document war, photographing five different wars of the early $20^{\text {th }}$ century: the Spanish Civil War, the Second Sino-Japanese War, World War II (including the Normandy invasion), the 1948 Arab-Israeli war, and the first Indochina war (Photo Seminars). 
first photojournalist killed in Vietnam, when he stepped on a landmine while photographing troops outside Thai-Binh (Brittanica.com).

Photographer Dickey Chapelle took this attempt to capture the "dramatic effect" of death on the battlefield one step further when, on November 4, 1965, she was wounded by shrapnel while embedded with a U.S. Marine division. As she lay dying, she asked photographer Henri Huet to take up Chapelle's own camera and capture her image as she received the Last Rites from a Marine chaplain (Fig 8). In this case, the Operator becomes the Spectrum, and then becomes specter herself. ${ }^{2}$

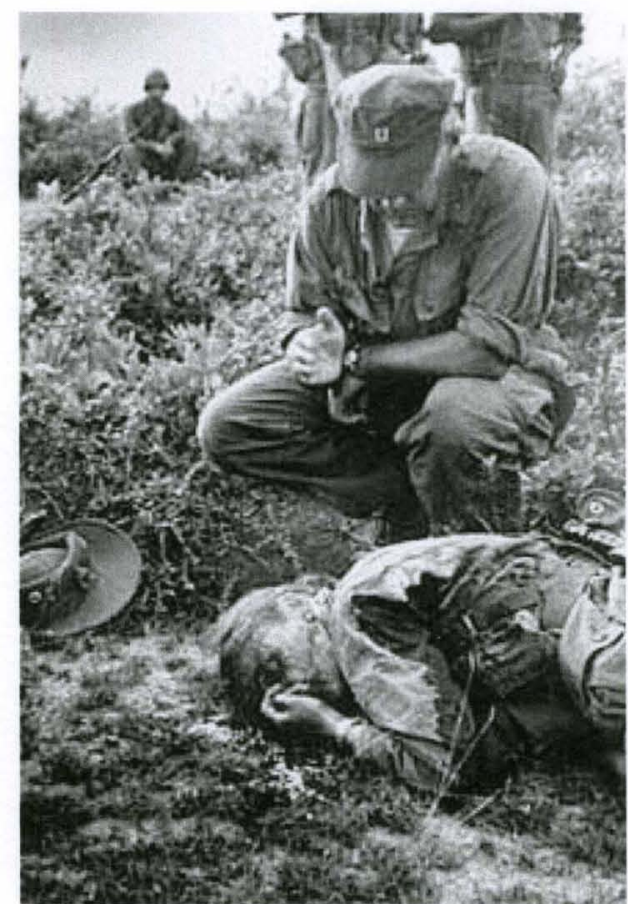

Fig. 8 : Henri Huet, "Untitled," in Horst Faas and Tim Page, Requiem (New York: Random House, 1997) 139.

Again, the photo imparts an unsettling kind of intimacy. This goes beyond mere memorializing. This is stepping into the moment of death through the image, and with

\footnotetext{
${ }^{2}$ See Chapter XIII for "Elegy to Pearls," a poem written about this photograph.
} 
this, the sanctified, private moment of death is ruptured. This is a disruption of the ritual of death, a fleeting and sacred moment made both permanent and public through art. What the corpse loses in this is a cultural meaning of its sacred space, just as it did in Rembrandt's painting when the body was opened up for public inspection. The corpse's meaning moves beyond the living person who once inhabited it and into the realm of object and text. 


\section{CHAPTER VIII}

\section{A BRIDGE TOO FAR: JOEL-PETER WITKIN AND GODS OF EARTH \& HEAVEN}

...[It is] the powers of silence and immobility which belong to and define all photography...The photographic take is immediate and definitive, like death and like the constitution of the fetish in the unconscious, fixed by a glance in childhood, unchanged and always active later. - Christian Metz, on Joel-Peter Witkin (Levi Strauss 53).

Metz's words invoke Barthes ideas of animation, the way a photograph has the ability to advene the Spectator. During this process, something in the unconscious of the viewer becomes "active later" on being triggered by the image captured in the photograph. In the case of controversial photographer Joel-Peter Witkin's work, this statement also helps to explain the genesis of Witkin's photos, much of which utilizes corpses and body parts to invert (some would say pervert) the sacred through disturbing meetings of disparate cognitive and symbolic categories. The photos are, Witkin states, "not of people but of conditions of being," and this condition is Douglas and Leach's liminal space (qtd. in Levi Strauss 54).

Much has been made of Witkin's professed first conscious memory. At the age of six, he was walking with his mother to church and witnessed a terrible car accident, which resulted in a severed head settling to rest at the curb by his feet (Levi Strauss 53). This image became the moment of stillness - and the fetishized object - he would return to in his work throughout his career. He continued his explorations of death as a draftee during the Vietnam War, where he spent three years as a combat photographer "recording army deaths from accidents on manoeuvers and suicides" (Levi Strauss 54-55). 
"Witkin has said he wants his photographs to be as powerful as the last thing a person sees or remembers before death" (Levi Strauss 53). This is the essence of Witkin's desire to capture the liminal space between life and death, and it also speaks to the aggressiveness his photographs demonstrate in this pursuit and the violation that many perceive on looking at them. Like Robert Mapplethorpe, Witkin raises moral, ethical, and religious voices against his work. "People don't just say 'I like them' or 'I don't like them.' They say, 'I object to them. I think they're wrong'" (Levi Strauss 54). Witkin's photographs traverse so many distinct symbolic categories they are akin to a chaos of overlaps, and its the pure number of liminal spaces created by his work that tip his images, for many viewers, from the sacred side of taboo to the profane. Figure 9 , "The Kiss," is one of Witkin's most well-known photographs and example of a flashpoint piece for Witkin controversy.

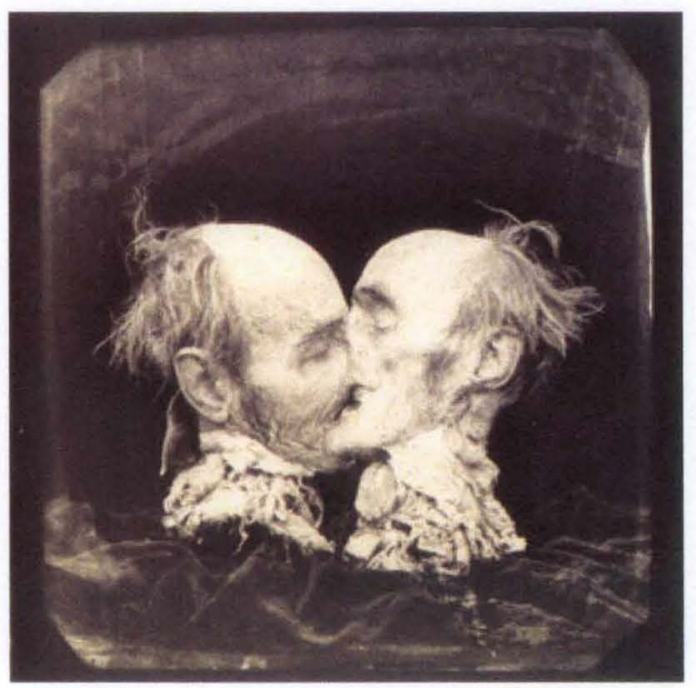

Fig. 9: Joel-Peter Witkin, "The Kiss," Gods of Earth \& Heaven. (Santa Fe: Twelvetrees Press, 1994) 52. 
"Counting Lesson in Purgatory" (Fig. 10) is an excellent example of Witkin's use of the corpse and the photograph to construct both an artistic interpretation of liminal space:

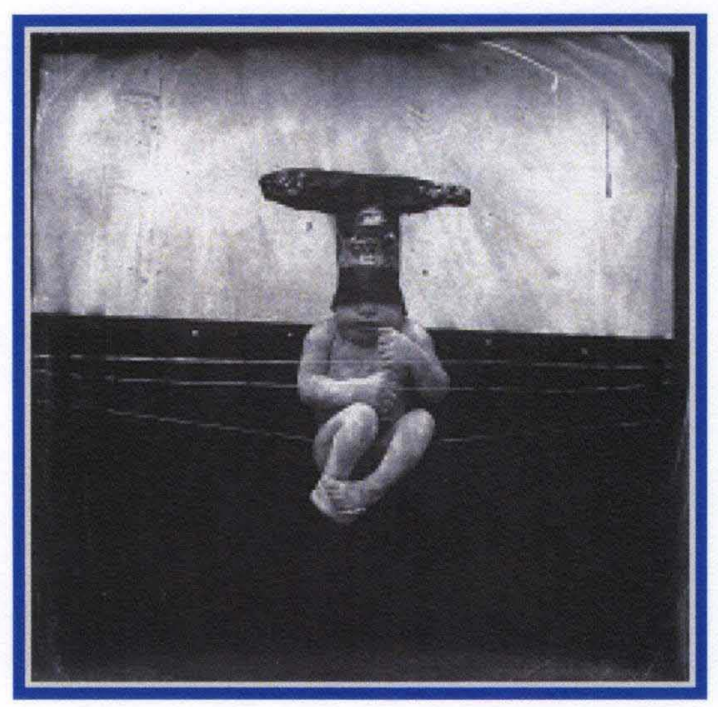

Fig. 10: Joel-Peter Witkin, "Counting Lesson in Purgatory," Gods of Earth \& Heaven. (Santa Fe: Twelvetrees Press, 1994) 6.

The studium of this photo is, as the title of the photo describes, Purgatory, the "holding area" between Heaven and Hell, and also between Heaven and Earth. The symbolic values of black and white and their connotations of opposites hold this liminal quality, the depth of black in the bottom portion of the photo growing deeper as the viewer's eye moves from the clear line demarcating dark and light. The sweeping curved lines at the top of the photo - ostensibly marking the margin of Heaven or the Divine, invoke medieval images of the firmament, a bubble that encased the Earth, an aspect further accentuated by the dark border around the light space.

At the center of the photo, and acting as both is Specter and its punctum, is the corpse of a stillborn, encephalitic infant, though with the addition of the odd stocking cap 
the Spectator is unable to see that the infant's head is absent above the brow, making it appear eeriely intact. The genderless figure's arms and legs are still curled in the fetal position, since, being born dead, it retains the position it held in utero. It is covered in a white film, invoking the spotty vernix caseosa just-born infants wear on their skin. The baby's thumb is poised before its closed lips, invoking both the image of a baby sucking its thumb for comfort, as well as Witkin's "counting lessons" mentioned in the photograph's title. It's as though the child is counting something (perhaps days in punishment) on its fingers, though the picture freezes this sum at "one," signified by the partially raised thumb.

The stocking cap is singularly strange. Clearly meant to imitate the shape of a uterus, it covers the infant's head in an inversion of the birth position, the entire mature body outside the uterine "cap," which still covers the baby's eyes and (absent) forehead. The two "arms" of the uterus (placeholders for the Fallopian tubes, though any suggestion of ovary is absent) are riddled with holes, and at the center of the arms, a photograph of an eye has been placed, reminiscent of the "All-Seeing" Divine eye (as on the back of the U.S. dollar bill). The "uterine" cap extends into the white field of the background, while the baby's body from the shoulders down is positioned in the black.

Traversing the photo's field, paralleling the demarcation between white and black in the background, Witkin has strung three pieces of piano wire. The lower-most wire supports the infant's legs, and the strain on it gives the wires the appearance of having entangled the baby's legs, holding it in place.

As stated earlier, there are many symbolic categories overlapping in this photograph. The largest overlap, and the one that gives the photo its disturbing quality, is 
the meeting of two opposing categories, "birth" and "death." The uterine shape of the cap, the fetal position of the infant, the actual use of an infant in signifying both birth and death all give the Spectator an immediate uncomfortable emotional response. The use of the infant crossed a cultural taboo in and of itself, since photographs of dead babies on display are rare except in cases of intentional appeals to emotion, such as those found in anti-abortion protests.

Since the uterine "cap" holds the eyes (signifying the Divine), there is an odd overlapping of the categories of "mother" and "Divine." Purgatory itself, artfully constructed in the photo by the white and black areas, and the piano wire that has seemingly "caught" the infant in between the Eternal (Heaven) and Earth and the Damned (Hell), holds many overlapping symbolic categories: "innocence" and "guilt", "good" and "bad", "saved" and "damned." Witkin's use of the infant as the conduit for these overlaps complicates them all, since most religions believe that one must have consciousness and experience to commit sin and thus be punished after death, and infants are not capable of willful sin. Even the Catholic faith reserves an area of the Afterlife solely for infants who die called "Limbo," since infants are born without human sin but are still marked with Adam's "Original Sin." This precludes them from entering into God's Paradise. The baby entangled in the piano wire is equally unable to "ascend" into the light, though the photograph specifically states this liminal space between Heaven and Earth is Purgatory, the place reserved for sinners to spend time to reflect and repent before entering the Paradise.

The photo is unapologetically religious in its intent, which furthers the blurring of categories by overlapping "religion" and "art." Add "death" to the blurring, and the other 
categories that are so clearly opposing in their connotations, and it's understandable why this photograph offends, since the integrity of sacred categories is breeched several times over. If one were to construct a Venn Diagram (as in Fig. 2) to show all these taboos conjured by Witkin's photograph, circle on circle would intersect. This shocking overlapping of symbols seems, in fact, to be the photograph's intent. The photograph reaches its effect by the construction of liminality in the overlapping cognitive categories to the point that the Spectator is unable to parse the symbols, and in this way the viewer is left with little other conclusion to reach about the image than that it is intended to shock or offend.

Nearly invisible in the overlapping of categories to form liminal space, though, is the photograph and the corpse themselves. The photo freezes the infant in death (Bronfen's corpse halted between beauty and decay), both of them invoking the Eternal that the infant symbolically cannot attain in the photograph's constructed situation. This doubling and redoubling of liminality in the photo and through the photo reinforces Witkin's construction of Purgatory, an unmapped and unseen landscape existing in many religious traditions after death. Like a drop of water frozen by a camera in mid-fall, death is halted in this photograph, the infant's corpse its conduit and the Spectator's substitute in its display. Through it, Purgatory is concretely constructed and the Spectator sees and experiences Witkin's landscape (depicted in the studium) where the soul is caught after death.

This photograph clearly both creates a liminal space. But to what end? This is a taboo space, yes, but is it reverent? Clearly not, just as Tulp's autopsy in Rembrandt's painting is not, with the body laid out and opened to reveal its secrets after death. But the 
difference here is that Rembrandt's painting, rendered in oil, does not freeze the actual corpse in eternity. It does not reveal the person-the dead person—in the stark way the photograph can. This is liminal space meant to manipulate the sacred for the artist's own ends, too purposed and too real, and the symbolism is can impart is eclipsed by the desecration of the body itself.

This is too much blurring even for liminal space. Meaning and subtext are vital to fine art photography, just as they are in poetry. But is the price of these metaphorical leaps - the dismemberment, positioning, and display of the human body in death-worth the meaning? In a murder case, these acts would be considered a desecration. Viewing these photos, it feels very much like they are here as well. The viewer is left to wonder what can remain of the sacred in this new kind of photographic, metaphorically constructed liminal space. 


\title{
CHAPTER IX
}

\author{
PHOTOGRAPHY'S TURN: SALLY MANN AND WHAT REMAINS \\ The earth doesn't care if a death happens on it. Its job is to efface and renew. The artist's job is \\ to remember it. \\ - Sally Mann
}

Virginia photographer Sally Mann took up this question in her book What Remains in what seems a counterpoint, if not a direct response, to the work of artists such as Witkin. At the time Mann published this book in 2003, the corpse had been opened, dissected, categorized, photographed. Death itself had few mysteries left, as medical science had parsed down its moments as succinctly as the photograph could capture and hold its final moments. Then artists such as Witkin had taken the body itself, posed it for the sake of subtext, and put it on display. What was left for the corpse and the grief surrounding it, lost in this new metaphorical, liminal, desecrated space?

Here, in Mann, we see a turn. Witkin conjured metaphorical meaning with the image of the corpse. But could the corpse and the emotions surrounding its commemoration be conjured without its presence? Could the meaning of death be found with the death of the individual absent, found only in its medicalization or in physical space?

If the corpse is the "ship of the dead," an object that, despite its stillness, has Taussig's "amazing capacity for travel," what happens when the corpse is absent but the 
Spectator still advenes because of it, still animates, still "travels?" This begs the question of whether the corpse is so much a part of the living's consciousness, so taboo in its connotations, that any other cognitive or symbolic categories that imply it conjure it like a ghost. Is the corpse present, still overlapping categories and settled in liminality, even when it is only suggested or invoked through image or place?

A return to Barthes may begin to answer these questions. When Barthes sees photographs of himself, even though he is aware that he is alive as the Spectator looking at himself (the Specter) in the photograph, he still experiences a moment of death. The referent and the suspended liminal moment of the photograph itself are enough to invoke Barthes-as-Corpse to Barthes when he looks at himself, even though the Specter is the living Barthes staring back.

But what if a Spectator looks at a photograph of a physical place and sees not the present space alone, but also sees the corpse implied (not present) in the landscape? This is the question that photographer Sally Mann wished to explore when she began her photographic exploration of death entitled What Remains.

The book is compiled in three parts. The first part primarily contains a series of photographs of the exhumed remains of a beloved pet Greyhound Eva and a photographic exploration of the famous "Body Farm" at the University of Tennessee in Knoxville (Fig 11 and Fig 12). The second part of the book is a series of photographs of famous Civil War battlefields, including those at Manassas and Antietam (Fig 13). The third and final 


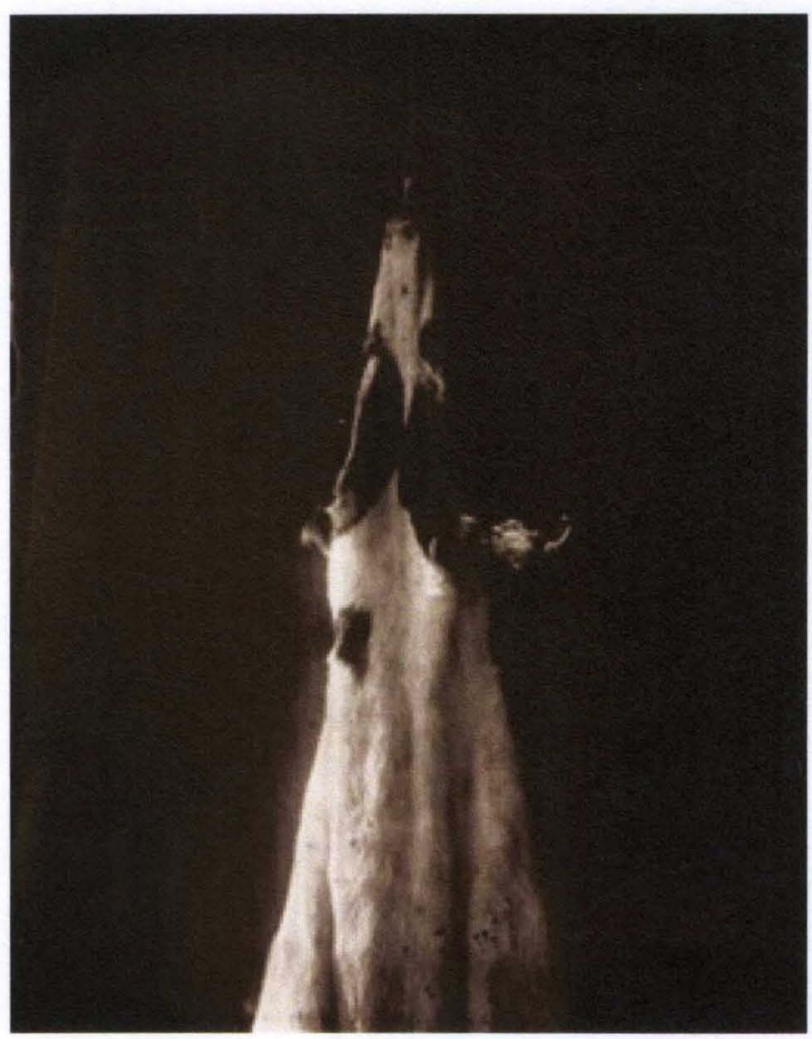

Fig. 11: Sally Mann, (Untitled), What Remains (Boston: Bulfinch Press, 2003) 9.

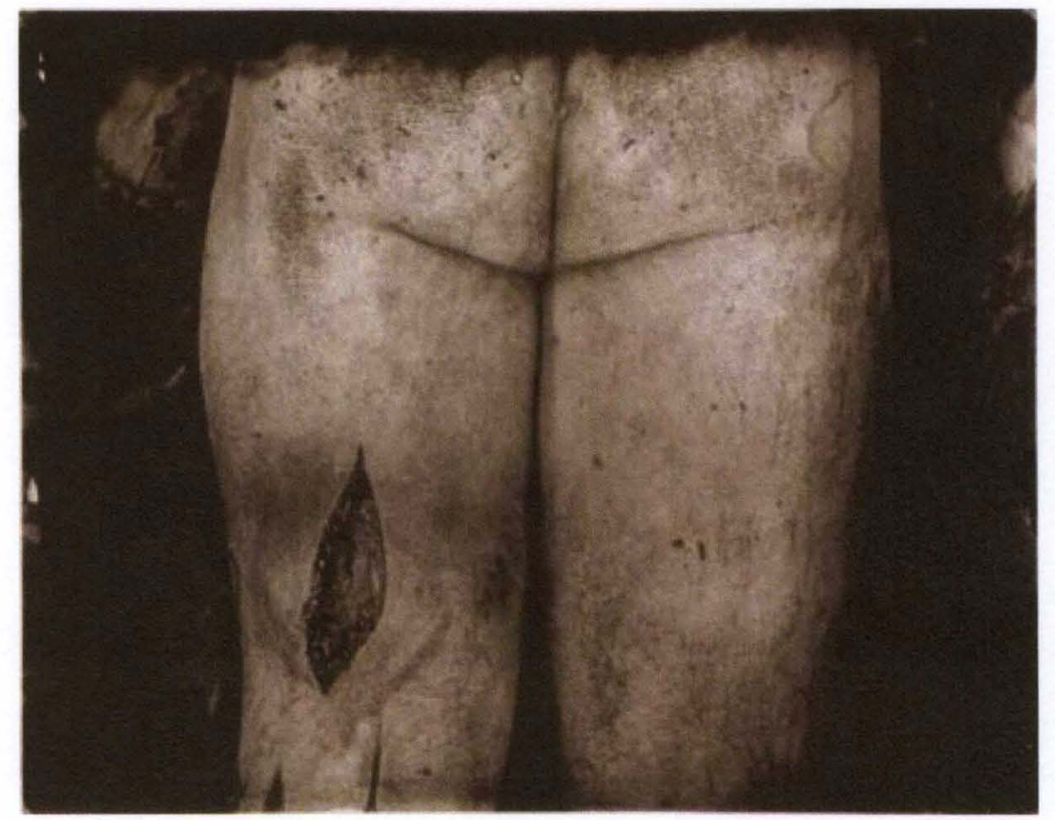

Fig. 12: Sally Mann, (Untitled), What Remains (Boston: Bulfinch Press, 2003$) 49$. 
section is made up of photographs of Mann's own children (Fig 14). Though the photographs are clearly intended to conjure images of death, the children are alive, photographed at their current age in the current moment. In these final photographs Mann attempts to show us "what remains" for her in her exploration of death - the perpetuation of life through her own children.

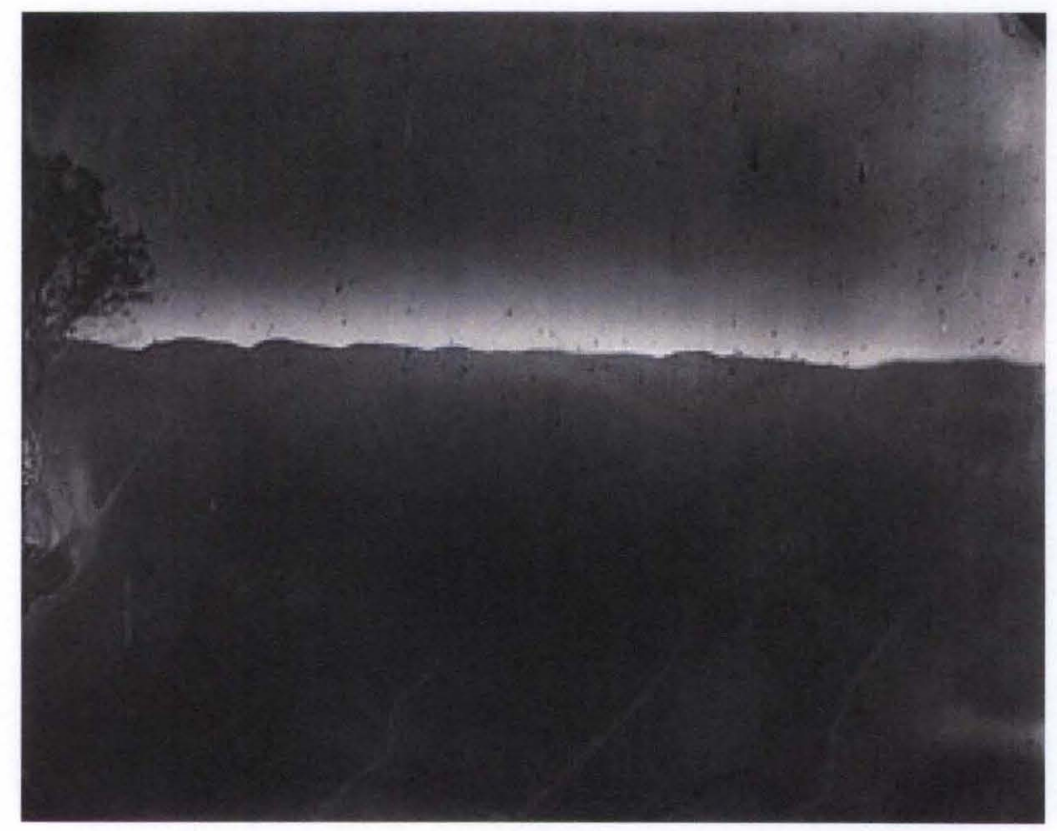

Fig. 13: Sally Mann, "Manassas \#15," What Remains (Boston: Bulfinch Press, 2003) 86. 


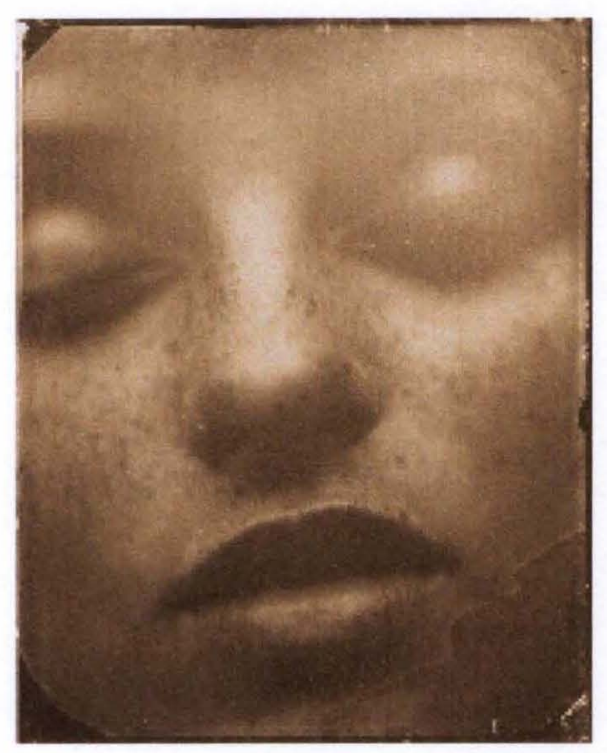

Fig 14: Sally Mann, (Untitled), What Remains (Boston: Bulfinch Press, 2003) 116.

Through her artful use of photographic technique, Mann is able to capture the liminal intersection of history and present and the cultural connotations of sacredness associated with death and physical space.

Figure 13 is an example of Mann's explorations of "what remains" of the dead when their physical point of discorporation is captured on film. It is a contemporary photograph of a famous battlefield from the American Civil War, the battlefield at Manassas, Virginia, a site of fierce and repeated fighting during the war where tens of thousands of men lost their lives. Though Mann's photograph (like Witkin's) is aided by its textual description, the Spectator need not know the specific history of the location being photographed to find something in it amiss. The photo owes a great deal of its "uncomfortable" advenience to its photographic technique, the arcane wet-plate collodion process. Developed in 1851 , this process is a method for making negatives on glass plates that have been coated with silver nitrate solution. The operator coats the plate, inserts it into the camera while it is still wet, and then has only five minutes in which to 
take the picture before the plate dries and loses its light-sensitive effect. In order to produce her battlefield photographs, Mann used this process and then placed the negatives on a plate of ruby glass, a dark, translucent material that reversed the image and thus produced the modern-day versions of wet-plate collodion photographs (Guiter).

The process is important both because of the way it invokes history in the dark, uneven surface of the photograph, and because its results are unpredictable and thus allow for random photographic effects. "Manassas \#15" seems to be vanishing into its own surface, the ground dark to the point of absence, and the horizon appearing to be the only source of light. If the Spectator did not know better, he or she would think this photograph very old, as though it were a piece of history and not a contemporary photograph, as though the Operator who took the photograph were already dead. The photo's appearance also imitates the decay of an actual photograph, which loses its sharpness over time and eventually disintegrates.

The wet-plate collodion process has also given rise to the illusionary of a "tear" in the landscape in the lower left corner, as well as a suggestion of the sky rolling back in the upper right. The landscape is specked with dark spots that appear to be both hovering and falling in their random shape and placement. Like Witkin's photograph, there is a clear sense that the photo is separated into darkness and light, the ground feeling like a "base" between the two poles they represent. Lines in the landscape invoke the image of scars.

The photographic process takes the place of the corpse in these photographs in order to imply the corpse's presence in the history of this physical space. The symbolic categories the process accesses in the Spectator involve his or her associations of history 
and the connotation of death such an extinct time implies. The photograph also implies destruction and decay through the flaws inherent in the random nature in the photographic process, which further overlaps with the symbolic category of death.

Mann began with the landscape, one often called "hallowed" or "sacred" by those who live on and around it, and sought to invoke these sacred connotations through the liminality of the photograph and the overlapping of symbolic categories related to history, photography as a representation of death, and corporal death itself. Like the living Barthes who sees his corpse in the self-portrait in front of him, the thousands of bodies that lay on the field at Manassas are created not before the Spectator's eyes in the photograph's studium, but rather behind his eyes, which look on the ground as "holy" by their implications with death and sacrifice and delineate these battlefields as what they are called throughout the Civil War states. They are not simple fields. They are sacred space.

This is a marked shift in the use of photography to commemorate death. Unlike Mathew B. Brady (who captured death through photos of the corpses of the Civil War) and Joel-Peter Witkin (who used corpses to convey both artistic representations and subtext to convey metaphorical meaning), Mann inverts these approaches as the book progresses from decomposing bodies to her lost dog to the battlefields. She now uses images themselves to conjure the dead and the meanings behind it—without using the corpse at all. Here in these images we see the losses of the battlefields. Here we see Brady's dead behind our eyes. Here we experience grief in "what remains" in the faces of her children, in those whose presence within the frame both reassures the photographer 
and the viewer and yet bridges the space between what is still present and what will one day be lost. 


\section{CHAPTER X}

\section{THE ELEGY'S TURN: SEAMUS HEANEY AND THE END OF THE "SACCHARINED DEATH"}

\section{The modern elegist tends ... not to override but to sustain anger, not to heal but to reopen the wounds of loss. \\ - Jahan Ramazani, The Poetry of Mourning}

\section{Whatever you say, say nothing.}

- a saying in Northern Ireland

Though there are many contemporary masters of the elegy form-Thomas Gunn, LiYoung Lee, Dylan Thomas, and to some degree Anne Sexton and Sylvia Plath-it seems none is as deft at using and also contemporizing the elegy form than the Irish poet Seamus Heaney. He is a poet who deals much with loss, both in a personal and social context, and his is a type of loss that has a particularly modern-even postmodern—bent. Heaney mourns not simply people, but a country, a way of life, and-in the end-his own personal identity within that country. By this I don't mean a "loss of self" in the general way we all lose ourselves in one way or another. This is the way a person loses him or herself to forces as uncontrollable and baffling as death: to politics and religion and, in Heaney's case, to the Troubles in Northern Ireland.

Yet Heaney seems to enter a sort of "tug of war" with the elegy form as he writes, embroiled in its conventions even as he seeks to redefine the form. In some of his poems - the poems for the so-called "Bog People" come to mind-the conventions are a nice fit, balancing present time with history and making use of elegiac conventions in a 
very effective way. (After all, if you're writing a poem about someone from the Iron Age, it seems only fitting that an older, traditional poetic form would be used to do so.) But in some of Heaney's other poems, especially "The Strand at Lough Beg," readers see how inappropriate these conventions can be in the face of uniquely modern circumstance, and how they can trivialize the event or person they are meant to honor. Heaney sees this as well; in Section VIII of "Station Island," readers witness Heaney's realization of the elegy's mistake, and we see a new, thoroughly modern turn in the form.

As discussed in the third chapter of this work, the traditional elegy is characterized by a number of conventions: pastoral contexualization, the use of repetitions and refrains, reiterated questioning and sudden, forceful outbreaks of anger or cursing by the speaker, traditional images of resurrection and rebirth, and echoes of myth and mythic figures (particularly the vegetative god or goddess) who is an immortal, earth-bound figure usually associated with the changing of the seasons. Other conventions often present include references to funerals, funeral processions, and mourners, as well as images of weaving, painting, or the creation of other forms of art.

To find these conventions in Heaney's work, one need only look to his poems about what P.K. Glob called "The Bog People." All of these poems—among them "Bog Queen," "Tollund Man," "Grauballe Man," and "Strange Fruit"-use many of these elegiac conventions, most notably the use of pastoral imagery and the vegetative deity. In "Bog Queen," for example, we see the conventions of the pastoral setting of the bog, the corpse's resurrection-like re-entry into the poet's reality, and references to the corpse as Sacks' immortal earth-bound deity. The corpse is, in fact, the speaker of the poem, a 
technique that gives her an immediate immortality. All of these elements can be found in the last two stanzas of the poem:

...Till a peer's wife bribed him

The plait of my hair,

a slimy birth-cord

of bog had been cut

and I rose from the dark,

hacked bone, skull-ware

frayed stitches, tufts,

small gleams on the bank. (Heaney 80-81)

Several of Heaney's other poems in his collection North— "Casualty," "Mid-term Break," "Funeral Rites"- utilize other elegiac conventions, especially the images of the procession of mourners, the echoes of myth, reiterated questions, and the use of concluding gestures in the poem to emphasize the speaker's surviving power over death. In "Casualty," an elegy written for an old man who was accidentally shot after breaking a Northern Irish curfew, we see the question of "...Puzzle me the right answer to that one," a question that is reiterated at the conclusion of the poem in "...dawn-sniffing revenant,/ Plodder through midnight rain,/ Question me again" (Heaney 115). The final question not only reiterates and emphasizes the earlier question, but it also places Heaney as the surviving power in the poem, the one still able to answer the dead man's question. The traditional images of a funeral with its procession of mourners is also found in this poem: 
Coffin after coffin

Seemed to float from the door

Of the packed cathedral

Like blossoms on slow water.

A common funeral

Unrolled in a swaddling band,

Lapping, tightening

Till we are braced and bound

Like brothers in a ring. (Heaney 117-118)

But perhaps it is "The Strand at Lough Beg" that uses the elegy's conventions in their most traditional Romantic manner. In fact, the poem sounds as if it were written in the Romantic period rather than in present day. The elegy opens with a quote from Dante's Purgatorio, which places it firmly in the Classical tradition. Then the readers are removed from the familiar setting of a town to the pastoral hills and forests of Northern Ireland: "Leaving the white glow of filling stations/ And a few lonely streetlamps among fields, /You climbed the hills toward Newtownhamilton/ Past the Fews Forest, out beneath the stars..." (Heaney 113). It is out in this pastoral setting that we next see Heaney question his cousin: "What blazed ahead of you? A faked roadblock?/ The red lamp swung, the sudden brakes and stalling/ Engine, voices, heads hooded and the coldnosed (?)"

According to Sacks, this kind of direct address of the dead is a way of "staving off...self-directed anger" (21). He goes on: "The so frequent, formulaic "where were you when?' may thus mask more dangerous 'Where was I?'" (22). I believe this is, 
indeed, the purpose of this section of the poem, besides its obvious purpose of revealing to the reader what actually happened to Colum in the Fews.

The poem also uses the convention of echoing ancient myth, both in its use of Purgatorio as an epigraph and in the final section of the poem where it alludes to Celtic/Irish mythic imagery. The last stanza deals with an imaginary encounter between Heaney and Colum:

I turned because the sweeping of your feet

Has stopped behind me, to find you on your knees

With blood and roadside muck in your hair and eyes,

Then kneel in front of you in brimming grass

And gather up cold handfuls of the dew

To wash you, cousin. I dab you clean with moss

Fine as the drizzle out of a new cloud.

I lift you under the arms and lay you flat.

With the rushes that shoot green again, I plait

Green scapulars to wear over your shroud. (114)

According to Barry Goldensohn's essay "The Recantation of Beauty," this cleansing image is meant to echo a myth from Heaney's childhood reading, the myth of Cuchullain and Ferdia, two legendary warriors who fought deadly battles during the day, and then bathed each other's wounds at night so they should go on fighting the next day until one of them was dead. It is also meant to refer to the gesture in Purgatorio of Virgil cleansing Dante of the stains of his passage through Hell with dew-soaked moss (77). 
Also, there is an echoing of another important elegy tradition, that of weaving, of creating fabric in the space of a void, a common theme in the elegy's history: "The boy on the carved bowl in Theocritus's 'First Idyll' plaits a cage of asphodel; the elegist in Virgil's Eclogue weaves a basket while he sings; the mourning Camus in Lycidas wears a carefully embroidered hem inwrought with figures dim; Tennyson, in section 66 of 'In Memorium,' compares himself to a blind old man winding the curls of children's hair...." (Sacks 18).

But in Heaney's poem, there is something empty in this image of his weaving the "green scapulars" for Colum's shroud. While the images are meant to end the poem with some sort of pastoral closure, they instead seem to unravel the ending, leaving it sounding hollow and unresolved. Goldensohn agrees with this reading in regards to the Celtic/Irish mythological allusion: "The moments of cleansing and healing are part of a heroic warrior code and a reminder of lost love and fellowship - they would be deeply inappropriate as a parallel to the death of Colum McCartney. Their ethical and heroic irony would...diminish —in the manner of the mock heroic — the senseless political murder" (77-78).

So there is a problem with the use of elegiac conventions in this poem; it seems almost that Heaney leans so heavily on traditional elegy conventions that instead of strengthening the poem, these devices weaken it. They seem hollow and inappropriate, "mock heroic." And if it reads this way to a common reader, surely it must have to Heaney as well. This brings us to a discussion of the elegy's "turn," as demonstrated in Section VIII of "Station Island." 
The long poem "Station Island" would seem to be Heaney's Purgatorio. But while Dante used that long poem to explore his own Classical vision of the afterlife, Heaney uses his to explore an entirely contemporary—and personal-Hell. But despite this similarity, there is one fundamental difference: Dante used his famous Circles of Hell to indict others, to show the consequences of immoral action, and in this way, he asked his readers to consider the rightness of their actions. Heaney, on the other hand, uses his long poem to indict himself in way that feels like a completely new repudiation in poetry, of poetry. He accomplishes this in a way that earlier recanters such as Eliot and Pound could not achieve because they had veiled their recantations ("Hugh Mauberley," "The Love Song of J. Alfred Prufrock") in a personae, one ultimately different, and distanced, from themselves (Goldensohn 78). While much of Heaney's poetry deals with what Goldensohn calls "reproofs" from the dead, such as in his poem "Punishment," when Heaney begins to allow the dead to accuse him of inaction, it is in the eighth section of "Station Island" that he does it most ruthlessly.

The action of this section is itself relatively simple: Heaney, in what the readers assume to be a dream, meets up with Colum McCartney, whom he elegized so conventionally in "The Strand at Lough Beg." And it is not a happy meeting. "The redhot pokers blazed a lovely red/ in Jerpoint the Sunday I was murdered/ [Colum] said quietly. Now do you remember?" (Heaney 202). Colum, the dead man, is speaking, for one thing, and for another, the tone is ominous. Accusatory. The reader is immediately aware of the precariousness of this meeting, of something distinctly out of sorts. Colum goes on: 
You were there with poets when you got the word

And stayed there with them, while your own flesh and blood

Was carted to Bellaghy from the Fews.

They showed more agitation at the news

Than you did. (202)

Heaney then attempts to defend himself, saying his friends were, in fact, more interested in the event of the political murder than the person murdered, than him. "I was dumb/ encountering what was destined..." This passage, this defense, is important in that it seems to echo the language of Classical, traditional poetry. Look at the inherent ambiguity of "encountering what was destined," and the difference in Heaney's language and that of his cousin. Heaney is speaking the language of "The Strand at Lough Beg," and it is a lame defense. With this line, and with the rest of the stanza, Heaney reintroduces the poem — and his mistake in writing it: "I kept seeing a grey stretch of Lough Beg/ And the strand empty at daybreak./ I felt like the bottom of a dried-up lake" (202). Colum is quick to respond:

You saw that, and you wrote that-not the fact.

You confused evasion with artistic tact.

The Protestant who shot me through the head

I accuse directly, but indirectly you

Who atone perhaps upon his bed

For the way you whitewashed ugliness and drew

The lovely blinds of the Purgatorio

And saccharined my death with morning dew. (203) 
One cannot help but feel the sting of this reply. It is here that Heaney repudiates himself in the mouth of his cousin, and does it so well, in fact, that it is hard not to imagine this scene as real, the words coming from Colum's mouth. But they are Heaney's words, for Heaney. As Jahan Ramazani writes in The Poetry of Mourning: "To redeem death in beautiful poetry is to legitimize it, to collude in atrocity" (346). But this is not the distinction that Goldensohn makes when he says:

Heaney is not... accusing himself of lying or propagandizing or comforting the enemy, nor grandly consoling himself for being merely human. The move is toward locating exactly where the moral danger lies: namely in that priestly posture that poets take on, dispensing grace and beauty when a colder and clearer vision is called for. (81)

In other words, this is Heaney's repudiation of the priestly stance of poetry (and poets) in the face of political revolution.

Other possible motives come to mind, as well. The poem could have been Heaney's way of giving his detractors-those Irish political camps that found him not "involved" enough at the time-a voice or acknowledgement. But after all, given the hopeless role of the artist in a revolution, torn between art and politics, how could Heaney himself feel uninvolved? And Heaney might have had a more personal motive, perhaps to address a family argument about his treatment of Colum's death. In the end, it is difficult to be certain his motives. But also in the end, there is an interesting irony, which Ramazani notes: "Though McCartney pleads for fact over art, this ghostly character is, after all, Heaney's latest artful creation" (347). And while this is true, his rebuke carries its sting nevertheless. 
There is more to this poem than this. Section VIII of "Station Island," I believe, marks the beginning of new elegy form, one that offers new conventions and new insight. First, the poem repudiates two major conventions of the elegy in two stanzas. He calls the pastoral context into question ("I kept seeing the stretch of Lough Beg...") and the echo of myth ("the way you whitewashed ugliness and drew/ the lovely blinds of Purgatorio...and saccharined my death with morning dew"). It is because of repudiations such as these, repudiations of poetry and the poem, that "Station Island" marks a sort of "elegy for the elegy." It becomes a form that Heaney finds no longer appropriate for marking death in the postmodern world. What Heaney has invented in its place is a new kind of elegy, one that mourns not only literal death but the deaths within the poet - the hopeless role of poetry in politics and the figurative death of the innocence of traditional poetry and its forms. Heaney, with Section VIII, gives the late $20^{\text {th }}$ century poet permission to elegize him or herself. This convention allows, in this era of the Fragmented Self, for an authentic and — and wholly modern—sort of grief. 


\section{CHAPTER XI}

\section{PHENOMENOLOGY AND POETRY: A METHOD OF EXPECTATION \\ "The body is our general medium for having a world." \\ -Maurice Merleau-Ponty}

If the act of reading and writing poetry were a philosophical discipline and not a form of art, it would be a philosophy of expectation. Through the use of carefully selected and arranged words, a poem seeks to directly impress a specific experience upon the reader, and this arrangement of words is based on a calculated - if benevolent -- manipulation of the reader's expections for the situation of the poem and for poetry itself.

This may sound like a distancing and reductionary explication of what is, in fact, a very emotionally centered art. But if readers of poetry reflect on the experience of that reading, they may describe some works as elusive or even inexplicable. This is not uncommon; poets and teachers of poetry often hear these descriptors from readers, and when students are pressed to elaborate, the student's bafflement typically comes from a disruption of his or her expectation of what the poem should say or of what a poem should be.

This begs the question, "What should a poem be," and from where does this expectation arise? A cursory look at poetic tradition suggests one answer: poetry is either written in the lyric tradition or the narrative tradition. It is written to express a single emotion or emotional experience, or it intended to relay some kind of story. 
Because of this general delineation in the poetic tradition, the vast majority of what casual poetry readers are exposed to will fall into one of these categories and thus will form what casual readers expect in terms of how a poem will express its meaning. Further, of lyrical and narrative poetry, readers of poetry are often more familiar - and more comfortable - with narrative works. After all, people grow up in a world of story, one filled with volumes of personal, familial, and cultural tales, one of which is history itself.

It's difficult to fault readers for their comfort, even if it often makes teaching forms which push against traditional bounds frustrating. There is a certain comfort to narrative. Consider this excerpt from Eavan Boland's "Writing in a Time of Violence:"

In my last year in College

I set out

to write an essay on

the Art of Rhetoric. I had yet to find

the country already lost to me

in song and figure as I scribbled down

names for sweet euphony

and safe digression. ... (Boland 18)

Readers are immediately grounded in a place, a time, a common activity, and an "I" who speaks in a familiar tone. This is a voice that brings with it a certain expectation for the reader. The reader will be told the content and significance of the essay the speaker is writing; there will likely be a disruption to the speaker's mind or heart while completing 
the activity, and from this disruption, the writer will impart some meaning. This is the way story works, because a story is rarely told without there being some meaning or moral for the reader to take away.

Now consider the reaction of a casual reader to another excerpt, this one from Chinese poet Duo Duo's "When the People Arose from Cheese:"

The songs ignored the blood of revolution.

August tautened like a cruel bow.

The malevolent son strode from the hut

with a pouch of tobacco and a parched throat. (Finkel 29)

In this piece of Menlongshi or "Misty" poetry from the Democracy Movement in China, readers are confronted with a work in which much of the familiar structure of narrative (and much of the lyric) is gone. Who is speaking and from where? Who is the malevolent son, and why August, and why tobacco and the "parched" throat? With the loss of traditional structure, the poem loses its shape for many readers, becoming a mishmash of image without form that could, without the proper reading - appear devoid of meaning. This is the kind of poem that causes some readers to protest that they don't "get" poetry, that the form itself is, at times, intended to be purposefully evasive or obscure.

This disjunction is not due to a problem with experimental poetry, and it is not with readers, per se. The problem is that the readers don't know what the experimental poem is asking of them or how to uncover the experience being detailed within it. The 
problem is, in short, that what readers don't understand about experimental work is that the experience the poem wishes to impart is an experience itself.

There is a philosophy that, when applied, is the antithesis of the expectation that drives much traditional poetry. Phenomenology, a school of thought and method of inquiry first detailed by philosopher Edmund Husserl, was intended as a response to Rene Descartes and the Theory of Ideas that was working to dictate the authenticity of lived experience. By applying his Method of Doubt, Descartes had deemed any perceptions existing outside the realm of natural science inherently false. Human beings lived in a "closed sphere of interiority" under this position, with "I think, therefore I am" the privileged view of a lack of connection between the objects of the outside world and the mind that perceives them. An experience of the outside world was, to Descartes, an idea. Only naturalistic science gave a "real" view of the world. The human being was reduced to a neurobiological entity, with some question existing as to whether the world required a mind of human beings at all.

Edmund Husserl sought to undo this view of the role of lived experience through a system known as phenomenology, a method people could use for reflecting on their own experience to seek the validity of that lived experience. The hinge of phenomenological method is this actual, lived experience, and the method has several key features, detailed in his book Cartesian Meditations: An Introduction to Phenomenology. The following is intended as a broad summation of this work's key points. ${ }^{3}$

Phenomenology relies on intuitive experience, meaning it deals with objects in the world that are self-given or there for the viewer in actuality. These were not remembered

\footnotetext{
${ }^{3}$ I am indebted to Dr. Osborne Wiggins for his lectures on Edmund Husserl, which make up the bulk of this summation of Husserl's work.
} 
experiences but ones that were experienced or re-experienced in the viewer's present. Phenomenology is also reflective, meaning that the viewer having the experience is actively reflecting upon and analyzing the experience. The straightforward experience how it unfolds and is given - is secondary to a rumination on the viewer's "take" on the affective quality of the experience. Husserl's method also deals with general or essential features of an experience, as though a type of experience (say, anticipation) had been placed in a crucible and boiled down to the essence of what differentiates that experience from others. These are the experience's invariants because to take them away would be to make the experience something else. The sum of these phenomenological features is a description of the experience, a verbal report on what is directly given by the experience upon reflection, and they contain only what is self-given by the object of experience.

It is important to note that this is an intentional process. For every mental process (or noesis) that takes place within a mental life, there is always an object of that process (noema). For every feeling, there is an object of that feeling. For every imagining, there is an object of that imagining. For Husserl, mental processes could not simply "think" and therefore "be;" they must be grounded in something other, something that brings the mind into awareness of the world and allows the mind to transcend itself and exist within and interact with the world. The active, intentional "doer" of this transcendence is the ego, an agent of awareness that thematizes our experiences. A person's mental life is aware of other things as well, but these are passive or automatic intentional processes, the constant hum and background noise of experience requisite with living in the world. Automatic intentional processes make up the horizon of our mental lives, things off in the distance that, while far off, can be brought into active 
intentionality by the ego should the mental process require or desire it. Through a switching between active and automatic intentional processes, human beings gain experiences from the world. Some of these experiences become the sedimentation of mental life and begin to comprise the way a person understands the workings of the world.

Though a complete discussion of phenomenology and its methods is outside the scope of this work, a few other aspects of its concepts are necessary for a discussion of its application to experimental poetic works. The first is important distinction between actual and potential experience. In actual experience (what can be grasped with the senses), there are also potential experiences. If, for example, a person looks at a steaming cup of coffee (the actual sense experience of sight and perhaps smell), there is the potential experience that the dark liquid will taste like coffee, and that it will feel hot when consumed. These potential experiences are predelineated, acting like mental "fences" the mind puts around its expectations for an object based on past experiences with objects with those essential features. Hot things will feel hot. Coffee will taste like coffee, and so on. Actual experiences are, Husserl says, originarily given, apprehended directly by the senses. The potential aspects are emptily given, implied and, by the nature of their implication, vague and ill-defined in terms of their actuality to the lived experience of the object.

Despite their vague status (the dark liquid that is originarily given by the senses could, in fact, not taste like coffee), human beings must co-intend their existence to make sense of what they see. The cup that holds the dark liquid does have a bottom. It must to hold the liquid. But though the senses cannot see the bottom, the mind co-intends that the 
bottom exists with what it can see, which is the rest of the cup. The bottom is part of the cup's inner horizon, a horizon that's not experienced by the senses but which must exist for the thing to be what the senses apprehend it to be.

Thus, the truth of what something is arrives when what is originarily given coincides with what the mental life emptily predelineated would be there. Or, to complete the example, when the dark liquid turns out to be coffee, and it is hot, and, when all of it is consumed, the bottom of the cup rests at the bottom of the cup. Though the world most often unfolds harmoniously and within the realm of these co-intendings, sometimes objects will violate these "fences" of expectation. When this happens (say, when the coffee turns out to be cold despite its steaming), the mind must "strike out" its previous experiences of a thing and begin again with the new originary experience.

From these originary experiences and their harmonious, reliable co-intendings, the mind constitutes the world. This does not mean that the mind actually constructs the world into reality because the world is real outside of the mind. But through synthesizing what's given and what's expected about the world, the mind is able to "map" the world and its workings in a manner of speaking. Objects in the world then become sedimented in the mind, and they eventually move into automatic perception. People do this with all objects in the world -including themselves - based on previous harmonious syntheses of those objects.

Another aspect of phenomenology vital to a discussion of experimental poetry has to do with the way the mind works with time as it goes through these processes. This working with time is called the mind's inner time consciousness, and it refers to the way 
the mind is able to ground itself in the present through a fluid "use" of past and future. This intertemporality is the most basic level of the mind's automatic life, the movement of the mind as it draws from the past (retending) to make sense of the experiences in the present, and then looks to the future (protendings) to push itself into its next moment. As a person speaks, he is aware of what he has just said in order to form the presently spoken words. This is retending. But the mind is also aware of where it is heading with what it's saying, and it pushes toward that. This is protending, and both of these movements to the past and future are necessary for the mind to understand its present, its now. The protending is a form of expectation, as is the retending. A person will move into the present based on the sedimented material of past experiences, bringing those beliefs (doxa) to the present moment. Likewise, she will look to the future with the expectation that objects and experiences will move as they have in previous experiences with those objects.

This is different than memory, which must be called into awareness. Retending is an automatic process, while mental processes such a memory are quite active. Protending is also different from anticipation, which is also an active process, while protending proceeds automatically. This distinction is important because in order to discuss the difficulty many readers have with experimental poetic works, it is necessary to look at how sedimented experiences affect this automatic retending and protending to affect the "now" experience of reading the work.

To move to the realm of poetry, it is necessary to look at words and their meaning. Though phenomenology is concerned with the sense experience of objects, Husserl did believe that words were objects in that they were capable of giving meaning 
in and of themselves. The meanings of words, he said, can be given in terms of experience.

From this, it follows that a work of literature and the experience of it can be the subject of phenomenological inquiry. A reader can reflect on the act of reading a work of literature as long as one has the originary experience of reading and is not operating from the memory of reading it. But to do this, a reader must evade the Modernist reliance on technique. Technique has overcome, Husserl believed, direct experience of a thing, which is the essence of phenomenology. People use a calculator, for example, rather than going through the process of working with the numbers involved in equations, losing meaning of both the numbers and the experience of their calculations in the process.

If Husserl was correct in his view that the world and its experiences were giving way to a reliance on technique over meaning, then modern poetry is a perfect example of the dominating presence of technique. The waning number of casual, non-academic readers for contemporary poetry and the common readers' resistance to non-traditional forms seem indicative of a stagnation of meaning within many readers' expectation of form and technique.

A trip to a local large-chain bookstore will give telltale signs of this. In the small poetry section of the store, several shelves are often devoted to books with titles such as 1001 Best-Loved Poems and Sonnets of Love, and while these volumes contain excellent examples of traditional forms, their dominance of the sales space gives a good clue about what non-academic readers of poetry prefer to experience. This leaves little room for less traditional - which is to say primarily non-narrative, experimental - forms of poetry 
among the general readership. In fact, the more adventurous readers of poetry must often specially order the books they seek because of the books' absence on the shelves.

The resistance is understandable, given that much of experimental poetry purposefully evades narrative forms and is thus very difficult for readers to understand. Without this dominant technique, readers' retending of what the experience of reading a poem should be (because it has been in the past) is ruptured. Thus, their automatic expectation, what they co-intend to be in place when they encounter a poem (story, meaning, moral) is also disrupted, and with this disruption, readers are left with an inability to parse the poem.

This is an important point because this is, in fact, what many writers of experimental poetry are exactly intending to do - rupture the narrative and the cointendings readers bring to poetry in general and about their poem in particular. This forces the reader into a phenomenological exercise with the actual of the poem, with the words themselves, and with the experience of reading the poem itself. The writer engages the reader purely on the power of meaning and not the familiarity of a narrative, story-like form. This in turn moves readers outside of the known and expected of poetry (their own retended and protended ideas about poetry and the experience of reading it), asking them to break out of the sedimented experience of their own mental life. For this reason, the application of phenomenological method to experimental poetry is one of the few ways a reader can fully apprehend the meaning of the experimental poem.

An application of this method to an experimental poem may help to clarify the ways phenomenology can help move readers into the now of reading non-traditional 
work. The following is an excerpt from Andre Breton's Surrealist poem "On the Road to San Romano:"

Poetry is made in a bed like love

Its rumpled sheets are the dawn of things

Poetry is made in the woods

\section{It has the space it needs}

Not this one but the other whose form is lent it by

The eye of the kite

The dew on a horsetail

The memory of a bottle frosted over on a silver tray

A tall rod of tourmaline on the sea

And the road of the mental adventure

That climbs abruptly

One stop and bushes cover it instantly ... (Caws 36)

In this application of phenomenological method, the object under scrutiny is both the physical poem, the experience of reading the poem, and the world the poem creates for the reader. To begin, a reader must have an originary experience of reading this piece. Once this is done, the reader may then reflect on this experience. Though it is impossible to speak for the entirety of all readers' experience of this experimental poem, a common reaction to Surrealist poems such as this one is one of confusion because of the purposeful manipulation of readers' expectations of the linear, narrative quality of poetry. In order to understand the poem's methods, it is necessary to "unbuild" the poem, taking 
the poem from its finished product to its most simple parts in a process that Husserl called Abbau. From these simple parts, the poem can be built again (Aufbau).

If a reader has read poetry before, he or she will have retended that experience and bring these retended experiences and co-intendings for what poetry is made up of to the originary experience of reading this poem. "This is an experience like those others," he will think, and move into this poem in that vein. From this, the reader will also have in mind essential features of what a poem is and how it works.

This is the beginning of the problems of the dominance of traditional forms of poetry, particularly the emphasis on narrative, in the mental lives of contemporary readers. Experimental poetry evades the very essential features readers are looking for, leaving the reader in the lurch for understanding how to parse the poem's structure. This also disrupts the harmonious synthesis of the retendings and protendings, the actual and co-intendings of the experience of the experimental poems as it's read. This is when the "strike out" begins, and the poem becomes inexplicable unless readers are willing to rely on the originary nature of the experience of the experimental poem.

The title is a good example of the undoing of expectation in this experimental poem: "On the Road to San Romano" sets the reader up for the experience of a physical road in some physical named place. But then the poem opens with an abstraction, an image that is completely unlike a physical thing: poetry (an abstraction) and it being "made" like love in a rumpled bed, which is then turned into "the dawn of things." The image juxtaposes again to something outside the "room" the reader has constructed to 
build the image. Next, the abstraction of poetry becomes "woods," moving the reader out further from the bedroom, now beneath the dawn, now into a dense wood.

The reader is already well outside the realm of story and traditional form. Now, with a typographical "trick" of italics, the poet also dissolves the voice, an implied contract with the reader, an "I" speaking who will be the hinge of the reader's connection with the "story" of the poem. Now, who is speaking, the reader asks? It's hard to know for certain, which is also the poet's intent, to dislodge the expectation of one authoritative, instructive voice. Then, after a brief discussion of the "form" that poetry has been "lent" (not given), Breton abandons even the narrative of the grammatical sentence and moves the reader into pure sensory image, pure Word.

If, as Husserl states, sensory (hyletic) data) is the basic unit of lived experience, this experimental poem also makes such a movement toward a fundamental sensory experience for the reader. The organizing idea of the mental life of the writer is to liken poetry and its attendant abstractions to something concrete and by abandoning narrative for pure image, Breton is both halting the work's poetic "time" as a narrative and making a commentary about the immediacy of experience required to understand poetry and its intent. He is, in short, inviting readers to have the same originary sensory experiences of the images for themselves and apply that hyletic data to an understanding of poetry.

So "the eye of a kite" becomes a vivid, visual image with attendant experience of height and flight; "dew on a horsetail" conjures tactile images of coolness, wetness, coarseness; "the memory of a bottle frosted over on a silver tray" invokes tactile images of the frigid cold of metal, glass and the bright visual of silver. The poem has performed 
its own version of $A b b a u$, taking itself apart to sensory detail. Then, when the reader is able to reflect on the experience of reading the entire block of sensory experience, he can perform his own Aufbau, building them up to the organizing theme of the poem, which is to explore what poetry - in all its abstraction - is. 


\section{CHAPTER XII}

\section{THE ARCHITECT'S BROTHER: ROBERT PARKEHARRISON AND THE PHOTO'S ABANDONMENT OF NARRATIVE}

Words divide, images unite.

- Otto Neurath, Austrian sociologist

Here we follow another turn in photography, this one taken by the photographic team known as Robert ParkeHarrison. The duo - made up of photographer Robert and his wife Shana, a choreographer — combines multiple mediums in their photographs, including photography, painting, sculpture, and elements of dance. In his 2000 collection The Architect's Brother, ParkeHarrison uses these techniques to create surreal landscapes that are, in many ways, more real than real. How they do this is a complex exercise in both the abandonment of realism and narrative and a pure reliance on the metaphorical value that can be contained in the image. Of his own process, Robert ParkeHarrison said this: "My photographs tell stories of loss, human struggle, and personal exploration within landscapes scarred by technology and over-use.... [I] strive to metaphorically and poetically link laborious actions, idiosyncratic rituals and strangely crude machines into tales about our modern experience ("Imagining a Shattered Earth: Contemporary Photography and the Environmental Debate").

This process is best explored by deconstructing one of ParkeHarrison's images itself. In "Earth Elegies" (Fig. 15), we see an example of the artists' surreal "capture" of 
metaphor in a constructed image. The piece depicts an imagined landscape, a wide, open, barren field under an overcast, leaden sky. On it, a figure (who is always ParkeHarrison himself in this collection, dressed identically in every photo) is pushing a sculptured, oversized ball akin to the type used in electric typewriters from the mid- $20^{\text {th }}$ century. From the posture of the figure pushing it, it is a cumbersome weight. The wheel, like its real counterpart, is covered with letters, symbols, and numbers, and the viewer can imagine that it is imprinting the symbols onto the ground as the figure rolls it across the field.

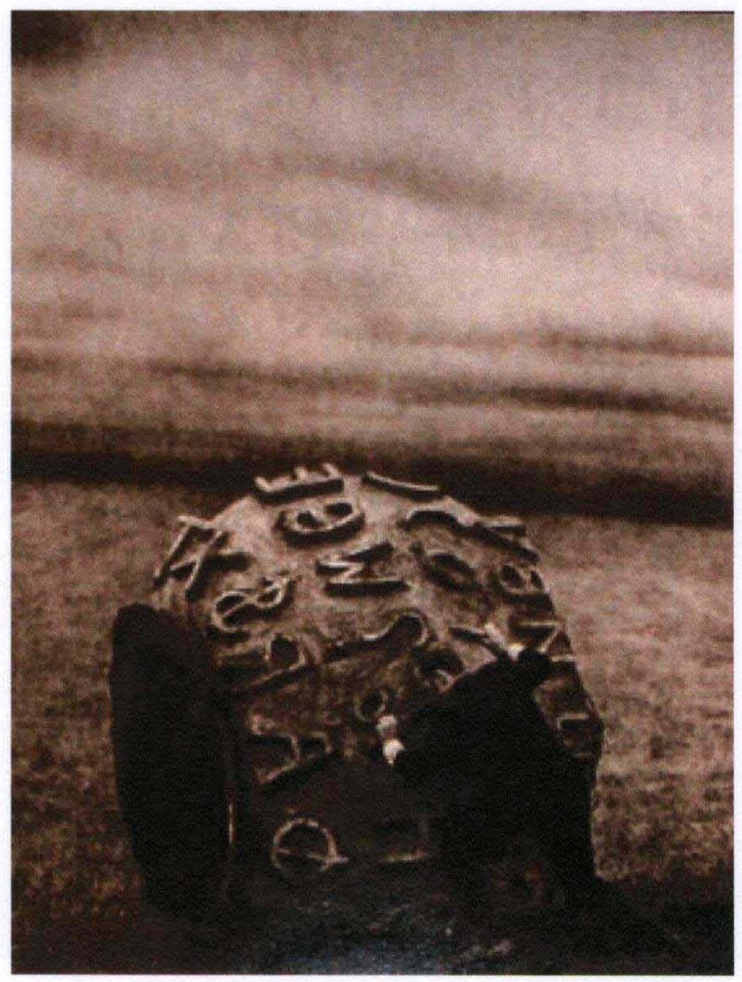

Fig. 15: Robert ParkeHarrison, "Earth Elegies," The Architect's Brother (Santa Fe: Twin Palms Publishers, 2007).

The entire collection The Architect's Brother has an unmistakably environmental focus, and "Earth Elegies" is one of the clearest examples of this theme. Here the figure is an 
agent of the "writing" of this "elegy," a work of grief for the dying land. Thus, it is about both culpability and grief for the forthcoming loss, as human beings (with ParkeHarrison as their representative placeholder in the piece) write the earth's ending with their actions.

The artist could have chosen to represent this theme with actual journalistic photographs of ruined rainforests, mountains with their tops blasted off, polluted rivers, landfills being filled with bulldozers pushing mound after mound of trash. But instead, we have this elegantly constructed photograph that encompasses the concepts and emotions of responsibility and mourning. By abandoning the actual, ParkeHarrison has found a way to explain what exists behind the real. Like Mann, he captures this death (in this case, the planet itself) without showing death at all. Grief is present without the human deaths like those depicted in the photographs of Brady or Capa present at all. Leaving the actual also keeps the piece from being tied to one situation-one Civil War soldier dead in Antietam, one stillborn infant - and instead universalizes the meaning, allowing viewers to enter the studium and find meaning there for them. Other examples of ParkeHarrison's work show how abandoning explicit narratives and their actual time and place can be perhaps more affecting to the viewer. Instead, he relies solely on constructed images that are capable of conveying a type of subtextual meaning that is immediate and affecting to the viewer. In "Garden of Selves" (Fig. 16), the technologically replicated figures (again, ParkeHarrison himself) lie tucked in the ground in grave-like boxes, all of them sleeping but one. One figure has awakened and looks up at the overcast sky that hangs over the assembled "selves" that extend to the horizon. In this garden - like the "garden of stone" image often used to refer to cemeteries - one part 
of the self rises in an image that is eerie and familiar. The complexity of the human being and his or her "selves" is captured here, as is the moment of realization of a piece of the self "rising," coming up like a shoot from the unconscious ground. An intangible, symbolic process is actualized here, made more real and comprehensible and affecting by being unreal.

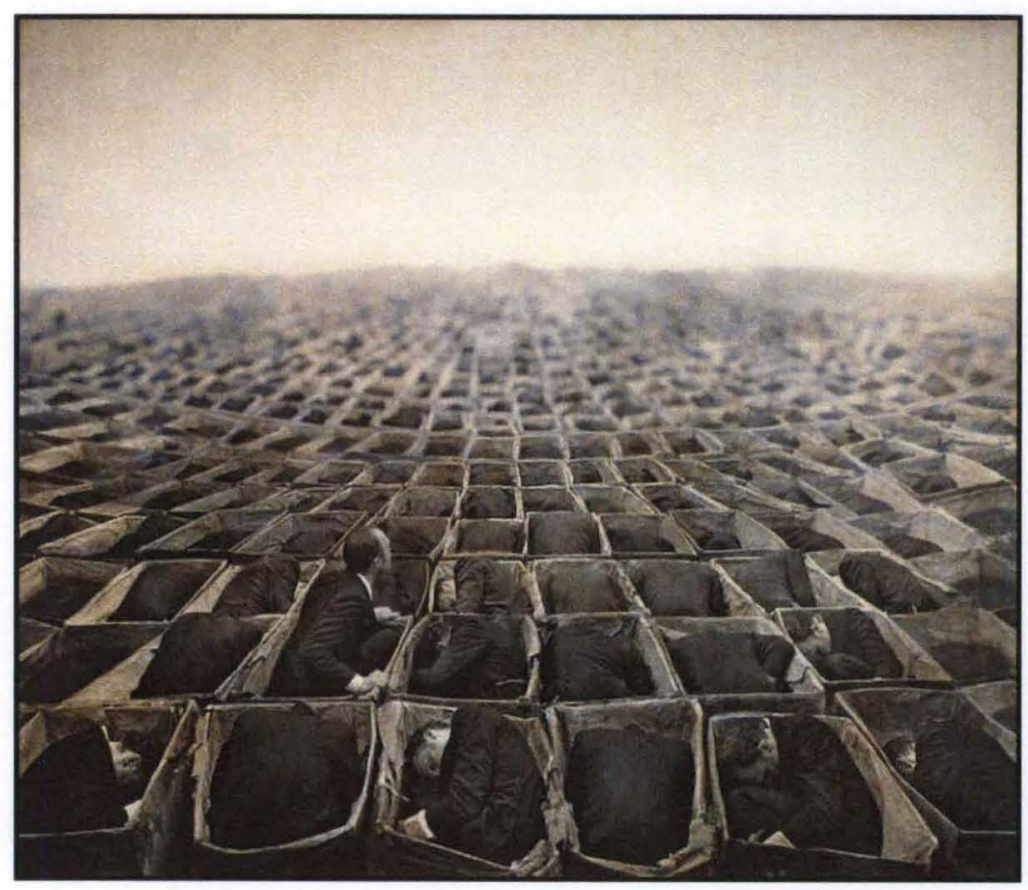

Fig. 16: Robert ParkeHarrison, "Garden of Selves," The Architect's Brother (Santa Fe: Twin Palms Publishers, 2007). 


\section{CHAPTER XIII}

\section{THE CLOCK FACE: A PLACE IN THE CANON}

\section{...The perfectly unseen is always preceded by the precisely seen, by a dependence on the visual image. \\ - Linda Bierds, poet}

Let us return to poetry to watch this creation of the unreal, this abandonment of narrative, transferred to the written space.

"The what what what of a helicopter gunship/ frozen in mid-air, 20 feet above the desert./ Fire one Fire Two Fire Three./ The chopper/ 180s back toward Baghdad. Target: "a terrorist/ safehouse..." So begins the second section of David Wojahn's "Dithyramb and Lamentation," a section titled "Epithalamium." He goes on:

The bride \& groom have entered, their mouths full of sweets

The band strikes up; the music crescendos, the wedding couple riding on a wave of shoulders, as an uncle, tiptoe on a chair, shoots video, a close-up of the bridegroom's face, then the shudder as the walls implode, target engaged. The Secretary of Defense, wire rims glinting, nods at the speakerphone $\&$ coughs. (22) The poem, part of Wojahn's Pulitzer Prize-nominated collection Interrogation Palace, elegizes a wedding party erroneously killed by U.S. forces in Iraq, the site of their wedding mistaken for a terrorist nest. 
If "The Strand at Lough Beg" felt empty because of its reliance on convention, and if Section VII of "Station Island" unsettled with its rising of the dead and its rebuke, this poem's abyss-like tone feels like a frigid wind. It is a poem of war, which Ramazani characterizes as a type of elegy, and it is an elegy to wedding party lost to a military (and political) mistake. But the elegy form is difficult to recognize in this poem other than in its occasion. The landscape is all but absent, as is the sense of mourning. The reader is not left with the dead but with Donald Rumsfield, the Secretary of Defense, his mourning of this loss a "cough" into a speakerphone from countless literal and metaphorical miles away, the scene both unreal and appallingly real.

Wojahn is a contemporary poet for me, someone swimming in the same cultural waters and in the same flow of poetic tradition and history. And though I am no Wojahn- - or Heaney, or Keats—-he and I both deal, as I mentioned at the start of this long exploration, with loss. But like Heaney - and perhaps because of him, in my case Wojahn and I do not work with the traditional elegiac conventions seen in the Romantic age. We write within both a Modern and Postmodern world, one that Ramazani says "sugarcoats mourning in dubious comfort, retreats from it in embarrassed silence, or pathologizes it, even locking it up in medical institutions" (ix). We write from a world where religious rituals are often abandoned, where the deaths of thousands at a time are commonplace, where death is often distanced from us by technology—speakerphones, televisions, computer screens.

And this world is also one where the landscape itself is difficult to rely upon, where seasons have become oddly altered, bizarre natural disasters frequent, blights and extinctions (witness the honeybee's growing disappearance) in the news. The landscapes 
of John Constable are difficult to find, and even when we do see an expanse like them, there is a certain unease. Will it remain? Worse, we are aware at this point in history that we are ourselves the cause of this unease, the ground moving beneath us as we move the ground.

Where does this leave the elegy form, and the poet writing it? Wojahn in his poem has lost his grief to politically rooted anger, taken on the screen and the camera and the speakerphone as his own devices and vantage point. For myself, the journey through these various fields has given me one way through this new, desolate landscape-that of an ever-expanding "horizon" of meaning, a way to abandon narrative in favor of discontinuity and simultaneity.

For the purposes of this discussion, I begin where I first came to the realization of a need to capture image over narrative, with a poem written in 1993 called "The British Apprentice at the Last Judgment." This poem was published as part of my first collection A Book of Birds (Briery Creek Press, 2008):

I.

The restoration apprentice has freed one arm, a shoulder, from darkness.

First, he applies water with a silken brush, then seven layers of ammonia-soaked paper that he presses to the painted man's face like a veil. As he works, he recites the chemistry of ancient paints: Burnt siene. Red lake. He knows too, this dirt made from five hundred years of bitter smoke prayers, knows every molecule and atom, every compound and pressure to remove it. But he can't help seeing the tallow's dark skin as sin that clings to this painting 
of a man staggering off a boat into a crowd, his face like a mask between his hands. A demon swings an oar against his back, forcing him off the water as through some terrible door, naked, barren -- desperate on a desperate shore.

II.

Whatever brought the apprentice to this chapel came in on horseback: Torn to bits was what his father had said, the way the bomb took them apart -his brother and his horse, the rest of the Royal Guard, a few from the stunned crowd in Hyde Park, all shattered by the canister dropped among them like a soft, black hat. For days after he imagined the scene: birds sent up from the wet morning grass; a bloody spray, six horses and men; his brother's pale and terrified face; running feet and distant siren wails; an explosion of Sinn Fein hate and carpenter's nails.

III.

At the time, he'd loved an Irish woman, a painter who worked in the nude. As she smoothed 
a landscape on canvas against the wall of their flat, he would lie beneath her thin white sheets and watch her from the back. When she painted the sky in her long, thick strokes, he saw the scene streaming from her breasts or the curve of her waist, then he'd hold her in a tight embrace as she made dark tea in the kitchen, the kettle whistling its shrill alarm as they kissed. After, she'd vanish into the bath and he'd sit naked on the bed and study every tree, every leaf, every flower stem on the slope of hill and look for some sign of himself. Knowing it was vanity, but knowing it was what he was supposed to do.

Enter her completely. Force himself into even this.

After that bomb went off in the park, he dared to speak of politics, to say that the I.R.A. were nothing but animals. When she did not reply, he told her the story from that evening's news: outside Belfast, two women, a faked roadblock, heads shaved and shot in the temple for snitching and fucking the Brits.

They had washed half the heavy white dishes. She held the ivory teapot tightly between her fingers, 
cold water running from the spout. She did not paint that night, or the next, the work now like a secret, somehow remote. A stiff blue flower she'd caught in her throat.

IV.

Outside now, in the Collonade, he remembers the Vatican guards waving their flashlights like sticks, pushing the tourists past Raphael and the rest as he brushes past a school of nuns gliding through a light winter mist. With his hands in his pockets, past the window where the Pope waits for Cardinals to bring him his meals, he thinks of politics and Cause, how intimate they are, how they work their way into what we see as ordinary, but that never really was.

Beneath the duomo and the Apostles turned green by the rain, he steps through a pool of black water, sees it all again: Michelangelo's figure, his face like a mask; two women with bald heads, their eyes closed against the shot; a flock of birds in a cloud of smoking wings; color pouring from a woman's thin waist; and blood pressed like paint to his brother's thin face. 
Looking at this work, I see a poem that is self-consciously narrative and tied to the real. Though the British apprentice is himself an imagined character, the rest of the poem is based on real circumstances. And it is not that this does not carry an emotional impact, but looking back at the work, I find its scope limited. The subtextual indictment of religion (specifically Catholicism) intended in the piece, for example, is so occluded by the stories the poem contains that it is all but lost. The stories depend on the reader's understanding of such details as Michelangelo's work, the Troubles in Northern Ireland, and the IRA bombing of Hyde Park in the late 1980s to be clearly understood. Overly long and consciously multi-parted and layered, the poem is encumbered by its own narrative weight.

Next, a later poem, this one "Elegy for Pearls," written in 1996 and also part of $A$ Book of Birds:

The battlefield's called Cold Harbor, though there's no water except the thin sheen of dew that lies like sweat across the meadow's brow.

But there is a gentle dip in the ground you could miss except for its persistence like a scar on skin. It's here the Union soldiers, trapped in the center of the field with a halo of cannon fire all around, were so desperate for shelter they dug that trench with their canteen spoons. It goes without saying that none of them survived, 
and in a few hours there was a cease-fire, the men still alive stepping into the trench and over bodies to trade coffee and tobacco with men they'd traded shots with moments before. In the end, none of it mattered, nor did any of them. The field was abandoned three days later and Richmond fell to men who walked the same field unchallenged, uncaring, unseen.

The man I'm walking with here can tell you the exact line the men followed as they scrabbled to this place. He can retell with the vigor that only the description of tragedy can muster how shallow the graves were, the slaves brought in to bury them quick in a summer thick with misery, death, and eventual defeat... And he will, if prodded, tell you how he loves to walk this place, how he finds it beautiful.

Which leaves me standing still, my foot brushing that trench's dent in the ground. I can almost feel 
the terror, hear the sound of metal desperate, scraping stone. See, things don't happen

like that and leave nothing behind and there's nothing beautiful about that.

Nothing beautiful about Dickey Chapelle lying curled on her belly in Chu Lai, November 4, 1965. Maybe the pearl earring peeking above her camouflage collar is beautiful, the gold watchband on the hand that's curled against her face like a sleeping child curls its fist. Maybe the wildflower is beautiful, the one tucked in the band of her bush hat that's tipped a few feet from the pool beneath her head. The pool would be red were the photo not in black and white, the photo taken with her own battered journalist camera, the photo captioned with her last words, the ones she breathed into the ruined ground:

"I guess it was bound to happen...."

But there's nothing beautiful about the picture she took in the Mekong Delta, 
1962, a Viet Cong man's eyes on the revolver

pressed in his face, and a South Vietnamese man

beside him laughing a second before the shot, a shutter click, the now-dead man's straw hat

turned up beside him, stark,

a bowl of overexposure.

Even now, years away from the photographs, The man, the battlefield at Cold Harbor, I close my eyes to that light.

And then I'm walking on a field

of rusted spoons, wildflowers marching

in rows, their hearts tiny, speckled, bloody

pearls, and all around the whole world's

unfurling like a tattered flag, singing out

cannon fire and laughter, singing

with the terrible shrill voices of angels.

I guess it was bound to happen --

the black and white jungle,

the grass on the silent meadow

that covers the trench, is thick and green

and growing behind my eyes. 
This ekphrastic piece, written after Henri Huet's photograph in Fig. 8, begins my own stylistic turn based on the image itself. The poem is clearly a transitional piece between two styles, half of it following the pattern of "The British Apprentice..." and half part of what will characterize a later poetic style based on surreal "lifting off" from the image into subtext and metaphor based on the image's liminal space.

The poem begins in narrative, a walk with a friend through Richmond's Cold Harbor Battlefield. Again, this is an actual, seen occurrence, though by the end of the encounter the speaker (who is me in this case) is beginning to interrogate the meaning behind the exchange with the friend. Next, the poem takes the classic turn of ekphrasis, describing Huet's photograph and adding details (such as Chapelle's last words) that could not be captured in the photograph itself, but which are still tied to the actual event.

It is only at the end of the poem, beginning with the stanza "And then I'm walking...," that the poem finds its way into the imagined world. The spoons from the first part, the ones the terrified soldiers used to dig the trench, are marching in rows, the flowers blooming Chapelle's pearl earrings. These cannot be real but they are real. They feel real. This is intended to capture the horrible disjunction of death and war, and as a poet, I found these surreal images were the best way-perhaps the only way-to convey what I saw and had come to understand.

Finally, the full-circle of these two styles, the creation of a constructed, liminal space through image alone, can be seen here in a 2008 poem called "New Year's Day," part of the collection that follows in Section II of this work entitled Loose Horses:

The view from here:

A frozen field, cut furrows of snow 
sprouting clock hands like wheat, sharp tips aimed at a sky the color of nothing but light. At the field's edge, birch trees rise filled of winter birds, coal knots on the thin trunks like eyes. Now the paint horse appears and moves across the rows in a brittle wind, its sides a pied canvas of rust and white. Where it steps, its hooves reveal the black lines of numbers, the frosted glass of the clock's wide face.

Conventional elegies use the pastoral landscape as a field on which to project the feelings of grief. "I kept seeing a grey stretch of Lough Beg/ And the strand empty at daybreak," Heaney says, the landscape real and untouched by Colum, apart from him. Now we elegize the pastoral landscape itself, the "brittle" rows, the lone horse moving across. And the uncertainty, the alienation of the present now becomes the landscape. The meaning of the New Year, the day, extends beyond the literal, embedding itself in the land, the land itself lost. Things are not as they appear, a "clock's wide face" beneath the landscape, its hands becoming the corn stubble, the corn itself gone. The poem, like this field, becomes its work of waiting - all of our waiting - the snow fallen over it like the poem's unspoken grief.

This is poetry as image, the image becoming Barthes' punctum. Here the poem becomes the spectrum, the poet the operator with her "take." The viewer is the reader, pierced by the image that advenes, ideally taken on a journey in this new kind of liminal 
space, one that regains a sense of universality, as well as death and grief and mourning's private, sacred place.

This is the space that Loose Horses is intended to inhabit and invite the reader to enter. It is a transitional book, marking the movement of my poetic style and voice from one that concentrates on narrative and narrative techniques to one that incorporates a concentration on the image and its power to "advene" in an effort to more accurately convey the poem's themes of commemoration and mourning surrounding both individual and cultural "deaths." In it, the reader will still find a heavy emphasis on narrative in some pieces. Others will "bridge" these two methods, while others will concentrate solely in applying this imagistic technique in an effort to extend both the images' meanings and the poem's ability to approach its theme.

If the collection is able to apply this imagistic, non-narrative technique and allow the reader to board this "ship of the dead" that moves from place to place, to reach some kind of universal understanding on the grief and culpability at the heart of the pieces, I will consider this long work to have achieved its desired effect. 
SECTION II: EXCERPTS FROM LOOSE HORSES 
Four horses cross the field in a row.

The draft horse, color of leather, in front, hooves skirted with long white hair. Head down.

The cold has made his halter stiff as plaster. I am behind him, his strong body blocks the blowing snow. Not far behind, two clay geldings trailed by a nut-colored mare.

The snow blinds. Hooves break the snow's ice crust. Our breath warm engines, a dry sound, sudden huffs of steam. My fingers crack red. I cannot see, but the horses know the way.

They have always known: In them are the ragged mountain passes, the battlefields where men stretched long blades between them to sever a charging horse's legs. Listen and you will hear the shrill siren in their throats, the heavy sound of their strong bodies falling. Later, the scuffle of hooves on the decks of ships in the Tropic's still air. Close your eyes now. See it the fear in the whites around their chestnut eyes. Now let go the thick lashing ropes and the deck rushes past. See them from beneath the blue surface of the sea, 
how they run with their strange jerked gait, chins up, nostrils flared in tough circles of soft flesh, the sun glazing the water as they turn to the horizon, to some safe land away from ships and men.

They looked on as we built and built, shied as the cannons scorched the air, strained across rough roads pulling carts of blasted rocks and men-Kiev, Flanderspulling wagons weighted with the frozen children from Bastogne, Belzec, Dachau. They fell from the shots as they dragged their insides, their ruined limbs, jerked their long necks back from firing squad tats. They grazed beyond broken stone fences as the dead of Gettysburg lay on the fields all summer, the corpses rooted open like sacks by black birds, swine, and rain.

And after, left to the meadows trailing their reins, the loose horses waited. They cropped the new grasses. They swallowed around their snaffle bits. They huddled in knots beside shattered houses, their saddles' girths rotting away, moved on when the fences came down at last.

We crossed impossible oceans. 
They waited in ships' holds for the beach.

We built our empires.

They watched from the forests, the hills.

This morning on the Antrim coast, I lost the trail along the Sligo Mountain as the storm moved in.

There I found the clay geldings, the fragile mare, the draft, snow falling on their canvas blankets, the cold Atlantic pounding the shore. They have always been with me. Look to the hard fields of our history and you too will find them, standing in their silence, somehow persisting, the pools of their eyes-dark as earth itself-looking back. 


\section{OVERHEARD: THE FATHER AND THE EARTH January 13, 2010}

The father sits on a broken stoop, his forehead against the heel of his hand. The striped shirt he wore to work the day before is open. Two small keys dangle from the breast pocket's flap. The daughter, 10-months-old on the day of her death, lies tossed among the bodies in the city square.

Her back is curved over a woman's breast. The woman is not her mother. The daughter's white shirt is caked with dust and pulled up over her swollen chest, her eyes slits in her smooth face and her mouth open, a dark $O$.

The father says to the daughter:

I am sorry, my little girl, that I was away from you when the ground began to shake, as though his strong hands could have shielded her from this world, this fate.

The daughter says nothing. Only dark flies, their bodies like green metal, leave her lips. So the father says to the Earth: If you're finished with her and the rest, then take them, damn you. Finish them, and me, and this. 
For a long time there is silence. The daughter's mouth grows darker as the father stares into it. The father is being lowered on a thick rope into a bottomless well.

The sky fades from bright gold to a deep bloody rust. Then, beneath him, the father feels the ground shiver and rise for one aftershock, one deep shake.

In that sound, the Earth answers:

Father, I do what I do, it says, What I have always

done despite all of you: what I must.

for Lionel and Christian Michaud 


\section{NEW YEAR'S DAY}

One-half of me becomes detached from the other: a witness.

- Nathalie Sarraute

The view from here:

A frozen field, cut furrows of snow

sprouting clock hands like wheat, sharp tips aimed at a sky the color

of nothing but light. At the field's edge,

birch trees rise filled of winter birds, coal

knots on the thin trunks like eyes. Now

the paint horse appears and moves across

the rows in a brittle wind, its sides

a pied canvas of rust and white. Where it steps,

its hooves reveal the black lines of numbers,

the frosted glass of the clock's wide face. 


\title{
THE PROFESSOR OF BEES
}

$$
\text { for Elsa }
$$

\author{
...with my tongue \\ I draw the black straw \\ out of you \\ meanwhile \\ with your tongue \\ you draw the black straw out of me. \\ - Jean Valentine
}

Someone is holding my hand.

Tell me about the world, she says,

and because we're high above the ground,

in a small plane heading east over mountains,

I say all right and rub a thumb

over her fingers, her soft, invisible

skin, fragile as glass.

Then I tell her how the world

is a jade door guarded with a silver lock,

and when you open it--if you open it-

beyond there is a golden lake

and a thousand thousand trees

and mountains made of bread.

You're making that up, she says, 
and because there are no lies

between us, I smile and say yes.

What are tears? she asks,

and because our trip is long, I tell her

about walls without roofs, windows

looking out on dark mountains, quarries

and mounds, sad rivers running past.

Stairs leading to boarded spaces and doors

bricked over. Ramps and carts, poles

dangling chains. A smoke stack

(the only exit) rising. A pyramid made of ash.

Train tracks buried in snow leading out and trees

wearing necklaces of rooks and crows.

Steps covered with ice, rusted silverware,

bone chips, gallows, broken bricks, broken

glass. A house of records, slots filled

to the ceiling, and a clock

stopped on the wall.

But I also tell her how

someone scratched the streets

of their home on one wall

of that place, and that wall remains. 
She blinks. Then who are we? she asks, and I shift in my seat, think.

Once, I say, people stood

at the base of a cliff overlooking the sea.

There were birds that nested on the beach, and birds paired on small ledges along the rock face.

The people wondered what would happen

if they switched the nests. So they climbed

and pulled down one of the wooden wreaths,

the thick nest of sea grass they perched

on the ledge still dusted in sand.

Then what? Her eyes are wide moons.

The eggs hatched, I said, and the chicks

on the beach, born to fear falling,

would not leave the nest. But high

on the cliff, the beach hatchlings

tumbled over the grassy lips

and disappeared.

There are coal mines below us, mountains, roads like veins. She nods, red hair, 
milk skin, eyes the color of grass.

That's hard, she says.

Now tell me something gentle, sweet.

So I tell her that before she was born, she was a bowl of fruit to me. Her mother said one week she was the size of a red grape, the next week a lemon, then a peach. An orange cupped in thicker skin. Her mother, a potter, stroked her own belly as though it were a bowl's round bottom, her hands moving as she'd learned to stroke clay.

We rise through the clouds.

The plane shakes and she is afraid.

And war? she asks, and seeing her fear, I say oh that, well, it's not as large as it seems. I tell her I've seen war fit inside a tattered hat -watched a widow given her dead husband's army cap hold the bowl of it to her face, 
close her eyes, and breathe

what she'd loved in and in.

And who are you? she asks.

Her hand tightens on my wrist.

Your mother's sister, I say.

She shakes her head.

Yes, but who? And what are you to me?

I say: Your mother was my hand

in the darkness, the sound of breathing

in my sleep. When I woke from dreams

that frightened me, I would hear her

there beside me, see her, and know

I was not alone in the long night.

We grew, grew apart, but I am part

of her, and you will be part of me.

Will you teach me always? she asks.

Yes, I say, for I was born

a professor of bees,

tiller of invisible fields

of difficult wheat. I sleep 
in a comb of rich, black silk

each night and drink words

the way you will drink milk.

We descend, and the child

leans in against me, finally

asleep. The earth seems to rise

from beneath. My lips

on her forehead, I say:

Little one, how you complicate

this flight. But I promise

we will write this life

together, each day a page,

even though you are born into waiting,

even though the bees are vanishing,

even though the wheat must be brought in.

And because I love you, Little Story,

I will not tell you that I've peeked

at our ending and know the world wins. 


\section{WHAT WE LOVE}

I walk my old dog down a street called Holiday, past trees whose white bark is trimmed with silver in the light rain of early Spring. The dog's small heart is failing and the vet's said he shouldn't be out, but if we walk slowly he can go four or five squares of sidewalk, then I let him stop and rest.

He puts his nose up into the cool air, the wind ruffling his black and white coat and the gray on his ears, the wind smoothing over him. When he can't go any further (halfway past that lovely ocre-colored house in my neighborhood, the one that's half-hidden by linden and guarded by an iron gate), I carry him against my chest.

One day a black lab stood at a driveway gate and barked at us as we passed. My old dog looked from beneath half-lidded eyes and didn't answer, and finally the other dog's owner, an older man, came out the screen door and called the dog to come back. The dog rose from where he sat, a hind leg dragging and his right-front hitched as he moved toward the house. 
I watched it go. The man looked at me holding my old dog against my chest. The man smiled. He raised a hand, half-greeting, half-regret.

I should say here that I know the rules I'm breaking.

I was told years ago that poets shouldn't waste their time on trivial things like dying pets.

"It's been done, and done, and done to death," a friend once said. And it has, sure as death's been done and done and done to death.

So I'll make a deal with you-forget what I've said about my dog in my arms, his nose in the air, the wind like hands. And forget the man and his black lab that limped up those brick back steps. I won't write about any of that. I'll write a poem about what we love instead.

What we love is a night and a house wreathed with linden, the dark kept outside a circle of light over an iron gate. It's fine as silver paper or the wind of early Spring. What we love is a tree that grows outside our window 
as we grow inside its panes, a small good thing

we bring home - or that follows us there -- one day.

Then it's a friend that walks with us, gentle

and welcome as rain. It's what we call to us to come

when darkness is coming, and it's what tends us,

and what we tend. And finally it's what we carry

close against us, feeling blessed as we hold it

and joy for what it gives and has given,

for the comfort it's been through hard, heavy days,

forgiving every burden it's been, grateful

for even the grief we must carry when it's gone,

that soft, warm, impossible weight. 
GOLD STAR

for Theodore U. Church

Haywheels, summer

stretching from the Bluegrass

to the broken ridges of coal mountains

in West Virginia. We are in a line of cars,

all of us flying flags whose centers

hold a single gold star.

We are bound for Arlington.

His Kiowa was shot down

outside Muqdadiyah,

and the body's been taken

ahead of us in an Army transport

for one last flight.

Gold star flags in our windows

(To help you stay together

on the road, the woman said),

over Red River, the Turnpike,

Crow and Goshen, Virginia.

In the car, music plays for hours. 
We don't know what's playing.

For hours, we don't speak.

Haywheels, coal mines.

Gold star flags.

Arlington-bound

like the family trips

of my childhood in winter

where I stood for hours

at the Tomb of the Unknown Soldier

and watched The Changing of the Guard.

Twenty-one steps. Twenty-one

steps, a clack of steel on black

shoes, the rifle spinning

like a prop, the guards in dark

glasses. At nine, I didn't believe

they were alive. I thought

they were the Unknown

and that every night, after the gates

closed and we all went home,

the family car drifting through

the city lights, one by one the dark men 
returned to the marble tomb-white as pearls-until sunrise.

It is foolish and wrong

to mourn the men who died.

Rather we should thank God

that such men lived.

A friend in his dark suit

at the memorial back in Ironton,

quoting Patton. The coffin-

color of pearls—draped

in a flag.

Terrible, I kept thinking.

At the funeral home, his false face

hard and brown as leather,

perfect uniform, medals,

high-and-tight, soft hair,

smooth, real forehead,

as though he wore

a helmet of his own head. 


\section{Beautiful}

and terrible, the Normandy vet

too palsied to salute but did.

And finally his young daughter's cry

as the Battle Hymn played.

I closed my eyes against it.

Take her out.

For God's sake.

Arlington, Section 60, the motorcade

inches behind the caison in the heat.

The band plays This is my Father's

World, blue and gold and white.

The rain stops at the graveside.

Ladies and gentleman, look to the sky...

Blackhawks low in the gunmetal blue, low enough to see their coal-colored sides, for the props to explode the heavy air, for us to see the lead pilot's face

turn toward us, the light glinting

off his helmet's mask. 
The crack and smoke,

a twenty-one gun salute,

and his daughter covers her eyes.

The colonel is down on one knee,

offering his wife and little boy

the folded American flag.

All around, red and blue, white

and gold catch in the sudden quiet,

the warm breeze.

Chief Warrant Officer 2

US Army

Feb 161975

May 282007

Bronze Star

Purple Heart

Operation

Iraqi Freedom

What can you do?

What can you say? 
We stand straight for the anthem.

She takes the flag. 


\section{NIGHT DIVE}

Night diving off the coast of Honduras

and everything feeding. The lobsters are black

and quick to back into the reef. An octopus

red as blood disappears in a puff of ink.

I am one beam of light probing the darkness

The surface, eighty feet above, is thin as skin.

Sea worms come, drawn to the light, swarm

around my hands and face. Their bodies

make a high-pitched sound like beetles.

They have no eyes. Only a mouth.

I turn off the lights and hang, suspended

in blackness, like the child that once grew

inside me hung in its own dark ocean.

He was smaller than even these creatures 
clutching my wrists like hands, relentless as the sea, tugging at me with cobalt hands of water. 


\section{BLACK PEARLS, GLASS BOAT}

on the occasion of our five-year anniversary

I.

Black velvet ribbons led to the edge of the ocean

through a forest of evergreens made of glass.

The footprints I followed were a woman's,

skin edged with soot, hair snow-dusted

and pulled back, and her eyes

were like a northern sea.

I know her well. We've made love inside this

glass forest, a soft wound path running through it

and us. Five years I have walked with her, both of us

leading strong blind horses - hers black, mine white.

II.

Golden fish washed up on the shore.

The footprints turn north, turn south,

the dents of them running along the ridge

of weeds walled up where waves have beaten 
the land like fists. But which way

to follow her, to find our way back?

The ribbons go south, wet and shining

as the moon rises, a bulb of bright glass.

III.

A cove of oysters, their white shells shining

and open like night blooms or young birds' mouths.

The water is clear as gin in the moonlight

and in each shell a pearl sits, black as a pupil

that sits in its blue iris and white shell.

The ribbons unfurl in an onshore wind

that smells of cassis and fig's leaves,

the ribbons' soft edges catching

on the anchor line of green boat

made of worn leaden glass.

I see her now, off on the horizon,

wearing a cape of mare's tail clouds

like a coat. 
I climb into the boat, push off this land

to find the way back, to her

and to all that we've known:

blue water,

soft black ribbon,

softer glow,

open mouths,

black pearls,

steady glass boat. 
This is the photograph I kept for myself.

I took it, developed it in its silver collodion bath

in secret so that when the horse appeared

on the plate I would be the first to see it, its ash nose

up above the surface of the bloody creek at Antietam,

its white shaggy sides slicked down with that water,

the caisson harness dragging behind it now

that the cannon had been blown apart and off.

But it was not the horse I was looking for. It was the boy

on its back. No more than nine or ten, a drummer,

smart Union uniform, hair mouse-brown and cropped

cap-short on his ruined head. You see, he had wrapped

his hands around the reins' leather straps most likely there

in the water, most likely as the horse (spooked

by the shots, the cannon fire, the shrill shouts)

crashed into that terrible water and swam

to avoid the blaze of fire on the banks.

That's where I took this picture - not in the heat

of the fight, no, but much later, feeling much the ghoul 
as the freed slaves gathered the dead into great burlap sacks.

The horse was still swimming up against the slow current

when I took it, the boy's body still draped across it

with his thin legs trailing behind in the water as though

the horse was running and the boy had risen off

in some glorious flight from its back.

I stayed in Washington much of the time after that

because of what I saw in the horse's eyes there on the plate,

saw in those black pools surrounded by wild fear's white.

I saw what this had cost the beast, and that boy,

and me in the dark room's strange light. So that's when

I hid this photograph-and hid myself--far behind

the lines and never went into battle again. 


\section{BLUE NIGHT}

For Liam Rector

On the plain, a round table

made of ice and on it, a silver

telephone ringing. I answer.

Blue night is coming,

an earthen voice says.

Blue night with a green river

of light running through it.

I look up. Beautiful north.

The wind is a long white note.

He tells me the story:

Here the raven came

when he stole the moon.

Here he changed

himself into an emerald leaf.

Here he dropped

into the woman's mouth and was born

a dark baby with oily eyes.

Here, he spent the cold nights 
in the shelter of his mother's arms.

Here he lay beneath a bear's hide,

his thin long fingers clutching bone

toys his grandfather carved. Here he slept,

warm and safe, but dreaming of flight.

His mother kept the moon hidden

inside an ancient jeweled box. One night,

he crept from the bed, his mother asleep,

and opened it, the moon's pearl glow

lighting his dark face. His arms stretched

to black wings again, his nose to beak.

The woman awoke, cried, ran to catch him

as he flew up through the smoke hole,

the bright moon clutched in his mouth.

Now the brown voice, bear voice

is lost in static on the long-distance line.

Above, the blue night is coming,

the cold moon wide as a child's eye,

the darkness shot with the green river

of the northern lights. And the man

with his black-quill stories is moving off 
now across the snowy plain,

a lone bear vanishing into all that white. 


\section{BLIND}

The sorrel mare in her stall, eyes clouded over, the card-Blind--slid into the stall's slot.

I knew she'd be put down but I went in with the bucket, the curry comb and brush, the cream that smoothes the tattered mane.

In the quiet, I called to her and her rust-colored head (shot with a snowy star) came up. When her nose bumped the wall, she blinked, jerked back, lowered it again.

But when I touched her, her lips found my hand.

When I touched her, she ran the side of her strong, warm face slowly up my arm to my shoulder and, seeking breath and the skin of my throat, rested her forehead there. Star to skin. Blind eyes shut.

When I moved, she moved. I stroked her side, the brush gentle and rough, cleaned off dried mud, old straw, the leavings of her last season's tough grass and snow and rain.

She was beautiful when I slid the stall door closed 
behind me. A perfect arc in her forelock, her eyes speckled moons in the ruddy dawn of her face.

I left her there beneath that place of high wooden beams, The faint lights hanging, bleeding brief and useless heat.

Cold sun outside the stable and on the frozen field. The cloud of rooks circles high in widening ripples, just as a shot's echo draws rings in the night's black air. This is a cruel season, and it can only end in grief. 


\section{SCRABBLE IN AFGHANISTAN}

At first, it was neonate, cameo, carry, slim. Just deployed, you found you were allowed screen time when back on base. You wrote that you feared this war not for its risk but for its boredom, so we found the game.

Pixy, yen, hiss, sin. In a letter, you say there is sand in everything - the food, your clothes, your eyes. I drop sunglasses in the mail, the ones rated to withstand a blast. You ask for soap. No scent, you say, in case I get lost out there.

Sometime in the night you play welt.

I answer, on waking, with jest.

Do you have any music? you ask.

Books? Anything? Don't care what.

You talk PT. Chow. Guard duty, Quick Response Force, Shank. 
Veins, dint. Then $d o$ and pi,

$m e$ and if. You resort to adding $s$ 's

to my words' ends. I write back:

Hey, stay with me over there...

Later, you say: I had something in mind

to do here. Do you remember what it is?

Two nights now, no word.

The screen glows, hums, blinks.

There in your wasteland, my young friend, dust off.

Plodder through sand and starlight, return.

Question me again. 


\section{REFERENCES}

Anonymous, "Victorian Post Mortem Photograph." 12 Dec. 2009.

$<$ http://www.estatevaults.com/1m/\%20\%20Victorian\%20post\%20mortem\%20photos1.jpg >

Arnold, Matthew. "Dover Beach," The Humanistic Tradition Book 5: Romanticism, Realism, and the Nineteenth Century. Ed. Gloria Fiero. Boston: McGraw Hill, 2006.

Barker, Francis. The Tremulous Private Body: Essays on Subjection. The Body, in Theory. Ann Arbor: University of Michigan Press, 1995.

Barthes, Roland. Camera Lucida : Reflections on Photography. 1st American ed. New York: Hill and Wang, 1981.

Boland, Eavan. Object Lessons: The Life of the Woman and the Poet in Our Time. New York: W.W. Norton \& Company, 1995.

Brady, Mathew B. "Dead Confederate Soldier, Petersburg, 1865." http://www.civilwar.net/cw images/files/images/695.jpg

-----. “"Confederate Dead, Spotsylvania County Courthouse, 1865." $<$ http://faculty.smu.edu/sweisenb/Conf\%20Dead\%20Spotsylvania\%20Cthse.gif $>$

Breton, Andre. "On the Road to San Romano," Surrealist Love Poems. Ed. Mary Ann Caws. Chicago: University of Chicago Press, 2006. 
Bronfen, Elisabeth. Over Her Dead Body: Death, Femininity, \& the Aesthetic. Manchester: Manchester University Press, 1992.

Capa, Robert, "Death of a Loyalist Militiaman," 1936, http://solitudesolitaire.files.wordpress.com/2009/02/death-of-a-loyalist-soldier.jpg

Collins, William, "Ode on the Death of Mr. Thomson," 3 October 2010. < http://www.luminarium.org/eightlit/collins/thomson.php>

Constable, John. "The Haywain," The Humanistic Tradition Book 5: Romanticism, Realism, and the Nineteenth Century. Ed. Gloria Fiero. Boston: McGraw Hill, 2006.

Craig, Emily. Teasing Secrets from the Dead. New York: Crown Publishing, 2004.

Crane, Stephen. The Red Badge of Courage. 4 July 2010. < http:// www.cs.cmu.edu/ rgs/badge-table.html $>$

Douglas, Mary. Purity and Danger : An Analysis of Concept of Pollution and Taboo. Routledge Classics. London; New York: Routledge, 2005.

Huet, Henri, "Untitled," 1964, Requiem: By the Photographers Who Died in Vietnam and Indochina. Ed. Horst Faas and Tim Page. New York: Random House, 1997. Faust, Drew Gilpin. This Republic of Suffering: Death and the American Civil War. New York: Albert A. Knopf, 2008.

Fiero, Gloria K. The Humanistic Tradition Book 5: Romanticism, Realism, and the Nineteenth Century. Fifth ed. Boston: McGraw Hill, 2006.

Finkel, Donald (translator). A Splintered Mirror: Chinese Poetry from the Democracy Movement. San Francisco: North Point Press, 1991. 
Fussell, Paul (ed). The Norton Book of Modern War. London: W.W. Norton \& Company, 1991.

Goldensohn, Barry. "The Recantation of Beauty." Salmagundi, 80:76 Fall 1992.

Guiter, Kristen, "Sally Mann: What Remains," Corcoran Gallery of Art, 12 Dec. $2009<$ http:/www.corcoran.org/exhibitions/press_results.asp?Exhib_ID=83>

Heaney, Seamus. North: Poems. New York: Faber \& Faber, 1985.

-----. Selected Poems: 1966-1987. New York: Noonday Press, 1990.

Heckscher, William S. Rembrandt's Anatomy of Dr. Nicolaas Tulp: An Iconological Study. New York: New York University Press, 1958.

Housman, A.E. Last Poems. New York: Henry Holt and Company, 1922.

Husserl, Edmund. Cartesian Meditations: An Introduction to Phenomenology (trans. by Dorion Cairns). Dordrecht: Kluwer Academic Publishers, 1999.

"Imagining a Shattering Earth: Contemporary Photography and the Environmental Debate," http://www2.oakland.edu/shatteringearth/artists.cfm?Art=37

Keats, John. "Ode to a Grecian Urn." The Humanistic Tradition Book 5: Romanticism, Realism, and the Nineteenth Century. Ed. Gloria Fiero. Boston: McGraw Hill, 2006.

Leach, Edmund. Anthropological Aspects of Language: Animal Categories and Verbal Abuse. Boston: MIT Press, 1964.

Levi Strauss, David. Between the Eyes: Essays on Photography and Politics. New York: Aperture, 2005.

MacDiarmid, Hugh. Collected Poems of Hugh MacDiarmid. New York: The MacMillan Company, 1967. 
Mann, Sally. What Remains. 1st ed. Boston: Bulfinch Press, 2003.

"Matthew Brady: Biographical Note," Library of Congress Civil War Photographs, 22 Sept 1997, 12 Dec 2009. < http://memory.loc.gov/ammem/cwphtml/cwbrady.html>

Owen, Wilfred. The Poems of Wilfred Owen. London: Chatto \& Windus, 1961.

ParkeHarrison, Robert. The Architect's Brother. Santa Fe: Twin Palms Publishers, 2000.

Ramazani, Jahan. Poetry of Mourning: The Modern Elegy from Hardy to Heaney. Chicago: University of Chicago Press, 1994.

Rembrandt von Rijn, "The Anatomy Lesson of Dr. Nicholaes Tulp," $1632<$ http://www.commed.uchc.edu/medicalhumanities/images/art/rembrant_anatomy_1 g.gif $>$

"Robert Capa," Encyclopedia Britannica, < http://www.britannica.com/ EBchecked/topic/93451/Robert-Capa>

"Robert Capa: 1913-1954," Photo Seminars, 12 Dec. 2009. < http://www.photoseminars.com/Fame/capa.htm>

Sacks, Peter. The English Elegy. Baltimore: Johns Hopkins University Press, 1985.

Schantz, Mark S. Awaiting the Heavenly Country: The Civil War and America's Culture of Death. Ithaca: Cornell University Press, 2008.

Taussig, Michael T. The Magic of the State. New York: Routledge, 1997. Tudor, Amy. A Book of Birds. Farmville: Briery Creek Press, 2008.

Turner, Brian. Here, Bullet. Farmington: Alice James Books, 2005.

von Max, Gabriel. Der Anatom. 1869. <http://www.niilismo.net/forum/images/ uploads/DerAnatom.jpg > 
Weigl, Bruce. "Song of Napalm." 4 July 2010. < http://www.poetryfoundation.org/archive/poem.html?id=171470>

Witkin, Joel-Peter. Gods of Earth \& Heaven. Santa Fe: Twin Palms, 1989.

Whitman, Walt. "The Artilleryman's Vision." 4 July 2010. < http://classiclit.about.com/library/bl-etexts/wwhitman/bl-ww-artillery.htm>

-----. "A Sight in Camp in the Daybreak Gray and Dim." 4 July $2010<$ http://www.civilwarpoetry.org/union/soldierlife/sight.html>

Wojahn, David. Interrogation Palace: New and Selected Poems 1982-2004. Pittsburgh: University of Pittsburgh Press, 2006. 


\section{CURRICULUM VITAE}

NAME:

Amy Liann Tudor

ADDRESS:

2309 Broadmeade Road

Louisville, KY 40205

DOB:

Atlanta, Georgia - November 2, 1968

EDUCATION

\& TRAINING:

B.S., English

Towson State University

1986-1990

M.F.A., Creative Writing

Virginia Commonwealth University

1991-1994

AWARDS:

Guest Associate Editor, The International Journal of Humanities

(Vol. 8, Issue 4) 2010

Al Smith Individual Artist Fellowship, Kentucky Arts Council 2010

The George Scarbrough Prize for Poetry: "Gold Star" 2010

University of Louisville Creative Writing Scholarship 2009

A Book of Birds-Winner of the Liam Rector First Book Prize for Poetry 2008

Literary LEO Poetry Prize, LEO Weekly: "Holy" Honorable Mention: "Jacob Rigby Builds the City of God" 2008

Professional Development Grant, Kentucky Arts Council 2007. 
Artist's Residency, Hopscotch House, Kentucky Foundation for Women

2007

Kentucky Opportunity Fellow, University of Kentucky 2004-2005

"Who's Who Among America's Teachers" (student-selected) 2004,2005

Outstanding Teacher in the Arts Award, National Foundation for the Advancement of the Arts 2004

Winner of the Devil's Millhopper Press Chapbook Contest The Land of Intention 1997

Virginia Commission for the Arts Individual Artist Fellowship 1995

Dean of Liberal Arts Scholarship, Towson State University 1987-1988

PUBLICATIONS: $\quad$ BOOKS

A Book of Birds. Briery Creek Press, 2008.

The Land of Intention, Devil's Millhopper Press, 1997.

\section{ARTICLES}

"The Holy Ground: Liminality in the Photograph, the Corpse, and Physical Space," The International Journal of the Humanities, Vol. 8, Issue 6, 2010.

\section{POETRY}

The Antioch Review

"Black \& White"

Winter 1996 
Antietam Review

"Kelso (for my mother)"

Spring 1994

Blackbird

"Untitled, with Peonies in Bloom"

"Self-Portrait with Eyes Closed"

Fall 2003

The Dos Passos Review

"A Book of Birds"

"Holy"

"Highway 51, New Mexico"

"Black \& White"

"Jacob Rigby Builds the City of God"

"Self-Portrait with Eyes Closed"

"Black Bicycles"

"Orange Tip"

"Untitled with Peonies in Bloom"

Fall 2007

The Georgia State Review

"The Land of Intention"

Fall 1996

The Louisville Review

"Requiem"

Spring 2007

LEO Weekly

"Holy"

"Jacob Rigby Builds the City of God"

Winter 2007

The Maryland Poetry Review

"Waking Before the City"

Spring 1994

The New York Quarterly

"Highway 51, New Mexico"

Spring 1993

New Virginia Review

"Elegy with Paper Wings on Fire"

Fall 1997

Open 24 Hours 
"Overheard: The Father and the Earth"

Spring 2010

Poetry Motel

"Kaffir Girl"

Fall 1990

Praxilla

"The Professor of Bees"

"Forget"

Winter 2010

Sow's Ear Poetry Review

"Miscarriage"

Fall 1993

PROSE

CONSEQUENCE Magazine

"Elegy with Wings Rising Inside It"

Winter 2011

Cream City Review

"Midnight Train to Georgia"

Fall 1995

The Louisville Review

"Mourning Cloak"

Spring 2008

\section{ANTHOLOGIES}

Turnings: Writing on Women's Transformations, ODU Press "Madness \& the $26^{\text {th }}$ Street Thrift Shop"

"Elegy for Pearls"

2000

Cameron's New Poets Anthology, Cameron Publishing "Last Ride on the Carousel"

1989 


\section{ART BOOKS/BROADSIDES}

The Shelter Project

"Blue Night"

Spring 2009

- collaboration with artist Hallie Jones

Longwood University

"A Book of Birds"

Spring 2008

- broadside by book artist Kerri Cushman

Virginia Commonwealth University

"Black Bicycles"

Spring 1994

- broadside by visual artist Sandra Masone

\section{FILM}

"My Story in the Late Style of Fire," a documentary film on the life of American poet Larry Levis, Michelle Poulos (director) and Kevin Gallagher (director of photography), 2011 (Interview).

\section{PHOTOGRAPHY}

Finishing Line Press

"Faces: Past, Present, Future"

Fall 2010

- cover photo for Julie Marie Wade's poetry collection Without

G.P. Putnam \& Sons

"Roots in the James"

Fall 1994

- cover photo for Sheri Reynolds' novel Bitterroot Landing

\section{CONFERENCES}

Panelist and Featured Reader, Larry Levis: American Poet, Virginia Commonwealth University, Richmond, VA, September 2010.

Panelist, "The Holy Ground: Liminality in the Photograph, the 
Corpse, and Physical Space," 8th International Conference on New Directions in the Humanities, University of California at Los Angeles, Los Angeles, CA, June 2010.

Panelist, "The Space Between: Exploring the Liminal Aspects of the Photograph and the Corpse," The Popular Culture Association in the South/The American Culture Association in the South Annual Conference, Wilmington, NC, October 2009.

Panelist, Creative Writing Presentation, "Selections from Loose Horses," Humanities \& the Arts: Cultures and Controversies, University of Louisville, Louisville, KY, April 2009.

Panelist, "A River to His People: A Celebration of Legacy \& Liam Rector." Associated Writing Program Annual Conference, New York, NY, January 2008 (with Mary Carroll-Hackett, Jill McCorkle...)

Panelist, Creative Writing Presentation, "Selections from $A$ Book of Birds," Literature and Culture Since 1900, University of Louisville, Louisville, KY, February 2007.

Panelist, Creative Writing Presentation, "Morpho Adonis," Historicizing Aesthetics/Aestheticizing History: Theory, Practice and Pedagogy of (Un)Making History, University of Pittsburgh, Pittsburgh, PA, April 2006.

Panelist, Creative Writing Presentation, "Selections from The Land of Intention," Twentieth-Century Literature Conference, University of Louisville, Louisville, KY, February 2002. 